\title{
Mindfulness for Musicians: Bringing sport psychology and mindfulness-based therapies to the practice room and the concert stage
}

Lauretta M. Werner

West Virginia University, Imw0013@mix.wvu.edu

Follow this and additional works at: https://researchrepository.wvu.edu/etd

Part of the Music Practice Commons

\footnotetext{
Recommended Citation

Werner, Lauretta M., "Mindfulness for Musicians: Bringing sport psychology and mindfulness-based therapies to the practice room and the concert stage" (2019). Graduate Theses, Dissertations, and Problem Reports. 3810.

https://researchrepository.wvu.edu/etd/3810

This Dissertation is protected by copyright and/or related rights. It has been brought to you by the The Research Repository @ WVU with permission from the rights-holder(s). You are free to use this Dissertation in any way that is permitted by the copyright and related rights legislation that applies to your use. For other uses you must obtain permission from the rights-holder(s) directly, unless additional rights are indicated by a Creative Commons license in the record and/ or on the work itself. This Dissertation has been accepted for inclusion in WVU Graduate Theses, Dissertations, and Problem Reports collection by an authorized administrator of The Research Repository @ WVU.

For more information, please contact researchrepository@mail.wvu.edu.
} 
Mindfulness for Musicians: Bringing sport psychology and mindfulness-based therapies to the practice room and the concert stage

\author{
Lauretta M. Werner
}

\author{
A Dissertation submitted \\ to the College of Creative Arts \\ at West Virginia University \\ in partial fulfillment of the requirements for the degree of \\ Doctor of Musical Arts in \\ Violin Performance
}

Mikylah Myers, DMA, Chair and Research Advisor

Edward Etzel, EdD, Research Co-Advisor

Erin Ellis, DMA

Lucy Mauro, DMA

Travis Stimeling, $\mathrm{PhD}$

School of Music

Morgantown, West Virginia

2019

Keywords: Mindfulness, ACT, MAC, Sport Psychology for Musicians, Performance Anxiety Copyright 2019 Lauretta Werner 


\begin{abstract}
Mindfulness for Musicians: Bringing sport psychology and mindfulness-based therapies to the practice room and the concert stage
\end{abstract}

\title{
Lauretta M. Werner
}

Due to the profession's competitive nature, time-consuming demands, and frequent evaluations, many musicians experience debilitating music performance anxiety, hypercritical thoughts, and/or avoidance of specific performance situations. To cope with these experiences, musicians can cultivate mindfulness. Mindfulness is purposefully and non-judgmentally paying attention to the present moment, developing awareness of emotions, thoughts, and physical sensations, and acknowledging the reality of one's experience. "Mindfulness for Musicians: Bringing sport psychology and mindfulness-based therapies to the practice room and the concert stage" discusses how cultivating mindfulness helps musicians cope with intense emotions, such as panic or fear, and explores how cultivating mindfulness helps musicians develop psychological flexibility, embrace acceptance, quiet their inner critics, soften perfectionism, and experience a desired state of flow during practice sessions, rehearsals, and performances. "Mindfulness for Musicians" references psychology and sport psychology sources, and reinterprets mindfulnessbased therapies and models for musicians, such as Acceptance and Commitment Therapy and the Mindfulness-Acceptance-Commitment model. Additionally, "Mindfulness for Musicians" includes tools to help musicians cultivate mindfulness, such as yoga practices, breathing exercises, exercise regimens, and meditation practices. Lastly, "Mindfulness for Musicians" includes a "Mindfulness for Musicians" course for undergraduate or graduate music students. The course includes a syllabus, a schedule, assigned readings, and a description of assignments. 
Mindfulness for Musicians

For my supportive family

For my inspiring past and present violin teachers 
Table of Contents

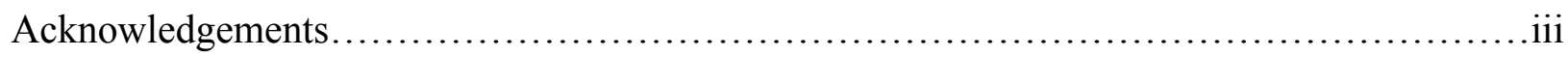

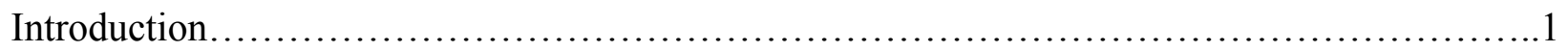

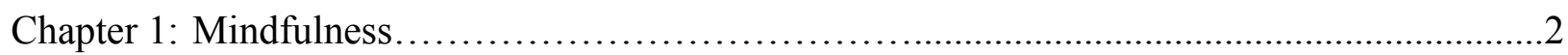

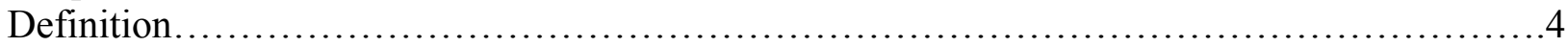

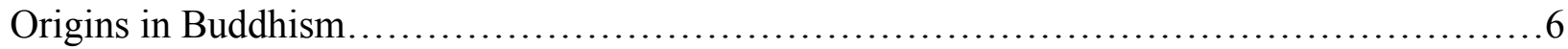

Mindfulness Practice Today...................................................... 8

What Mindfulness is Not............................................................. 9

Mindfulness in Western Medicine..................................................... 10

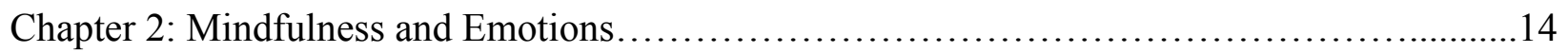

Chapter 3: Being in the Present Moment............................................. 18

Psychological Flexibility........................................................20

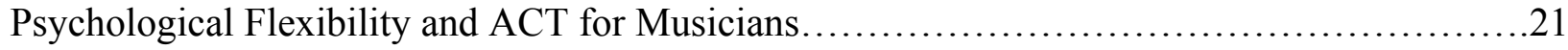

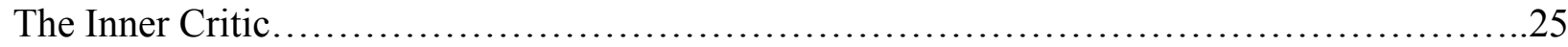

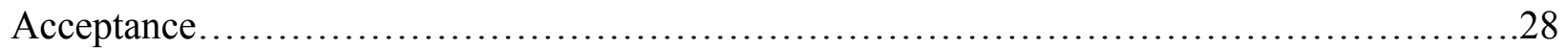

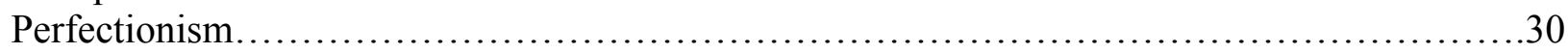

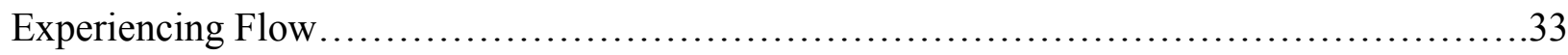

Musicians in the Present Moment...................................................... 38

Chapter 4: Mindfulness Exercises................................................. 42

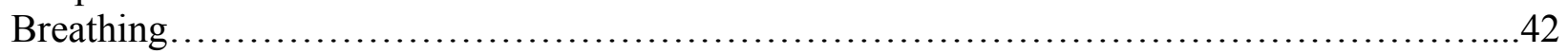

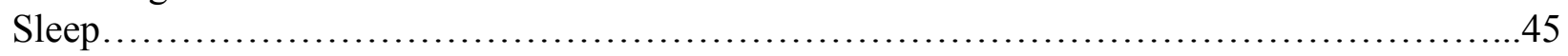

Rest and Recovery.......................................................... 50

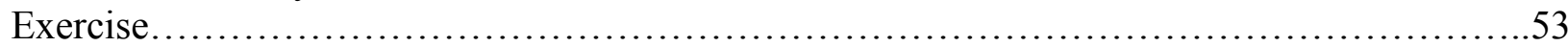

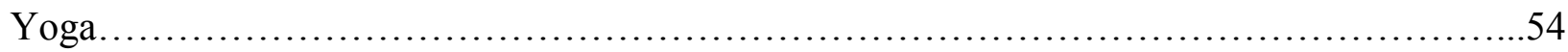

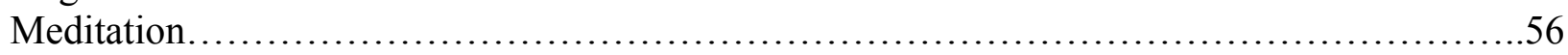

Chapter 5: "Mindfulness for Musicians" Course.................................................................59

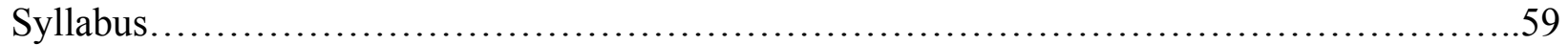

Course Schedule and Assigned Readings.............................................60

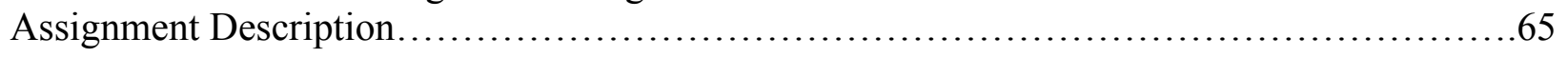

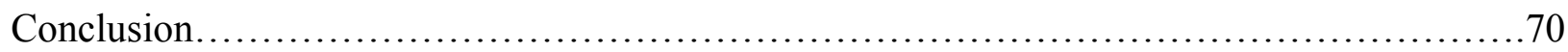

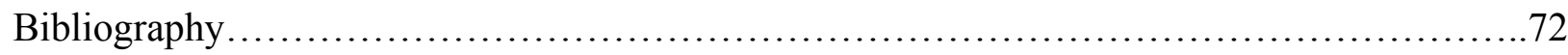


Introduction

The topic of this document focuses on mindfulness for musicians. Literature relating to this topic is summarized and reinterpreted for musicians. While there is considerable amount of research on the topic of mindfulness, no new experiential work was conducted for this document.

Due to the profession's competitive nature, time-consuming demands, and frequent evaluations, many musicians and music students experience debilitating music performance anxiety, hypercritical thoughts, and/or avoidance of certain performance situations. ${ }^{1}$ To cope with these experiences, musicians can cultivate mindfulness. Mindfulness is purposefully and non-judgmentally paying attention to one's present moment, and developing awareness of one's emotions, thoughts, physical sensations, and behaviors. ${ }^{2}$ Mindfulness focuses on noticing and observing one's present moment experience with openness and curiosity. ${ }^{3}$ When cultivated, mindfulness offers clarity and acceptance to one's present moment experience, and improves emotional health and self-regard. ${ }^{4}$ Because research on connecting mindfulness with musicians and musical training is new and limited, this document references several psychology and sport psychology publications that detail the advantageous results for individuals with anxiety disorders and high performance athletes who cultivate mindfulness, and reinterprets these findings for musicians. This document includes the following five topics: (1) defining mindfulness, exploring its history, and discussing its impact in Western medicine, (2) discussing

\footnotetext{
${ }^{1}$ Lydia Fehm and Katja Schmidt, "Performance Anxiety in Gifted Adolescent Musicians," Anxiety Disorders 1, no. 20 (Nov., 2004): 98-109, https://doi.org/10.1016/j.janxdis.2004.11.011, 99.

2 Jon Kabat Zinn, Wherever You Go, There You Are: Mindfulness Meditation in Everyday Life (New York: Hyperion, 2005), 4.

${ }^{3}$ Rezvan Ameli, 25 Lessons in Mindfulness: Now Time for Healthy Living (Washington D.C.: American Psychological Association, 2015), 4.

${ }^{4}$ Oscar Lecuona de la Cruz and Raquel Rodriguez-Carajal, "Mindfulness and Music: A Promising Subject of an Un-Mapped Field," International Journal of Behavioral Research and Psychology (2014): 27-35, https://doi.org/10.19070/2332-3000-140006, 28.
} 
how mindfulness helps musicians cope with intense emotions that arise during practice sessions, rehearsals, and performances, (3) discussing how mindfulness helps musicians develop psychological flexibility, embrace acceptance, calm their inner critics, soften perfectionism, and experience a desired state of flow, (4) offering mindfulness exercises for musicians to implement during practice sessions, rehearsals, performances, and in their daily lives, and finally, (5) including a syllabus, course schedule, and assignments' description for a "Mindfulness for Musicians" undergraduate and/or graduate music course.

Chapter 1: Mindfulness

Mindfulness

"Mindfulness means paying attention in a particular way; on purpose, in the present moment, and non-judgmentally. This kind of attention nurtures greater awareness, clarity, and acceptance of present-moment reality. ",

Jon Kabat-Zinn, founding director of the Stress Reduction Clinic and the Center for Mindfulness in Medicine at the University of Massachusetts Medical School, and pioneer of bringing mindfulness into Western medicine and other aspects of life, defines mindfulness as "moment-to-moment, non-judgmental awareness. " Cultivating mindfulness seems daunting and nearly impossible: How can one possibly maintain constant awareness of thoughts, physical sensations, and emotions all of the time? Mindfulness focuses on developing one's experiential awareness by recognizing when the mind wanders from the present moment. People's minds easily wander from the present moment because human brains are designed to think, analyze,

\footnotetext{
${ }^{5}$ Kabat-Zinn, Wherever You Go, 4.

${ }^{6}$ Karolyn A. Gazzella, "PhD: Bringing Mindfulness to Medicine," Alternative Therapies 2, no. 3 (May/June 2005): 60.
} 
and make connections. By cultivating mindfulness, individuals simply recognize when their minds deviate in thought, and return their focus to the present moment. ${ }^{7}$

Kabat-Zinn emphasizes how cultivating awareness is crucial for success in school: focusing for a period of time, sitting in one place for a length of time, and maintaining concentration over several hours. Although mindfulness is crucial for academic success, KabatZinn remarks that schools typically do not teach their students how to cultivate awareness of their thoughts, emotions, physical sensations, and behaviors. ${ }^{8}$ Music students, especially, need to cultivate awareness of their posture, intonation, pulse, and articulation, as well as awareness of their fellow colleagues, conductors, and students.

One may argue that musicians are already mindful because they tend to ignore distractions from friends, phone calls, social media, and food while playing their instruments. Although musicians allocate hours of their day for deliberate practice, they cannot always recall specific details from their practice sessions because thoughts, worries, insecurities, and physical pains may distract them. Additionally, musicians may perform poorly because during a performance, they fixate on a prior musical mistake, the audience's perception of their playing, or a pain in their body. When cultivating mindfulness, similar thoughts, insecurities, and worries can still occur during practice sessions and performances: "What if I am not prepared? What if I mess up this difficult section? What am I doing here - I shouldn't be on this stage playing this piece!" However, instead of dwelling on these experiences, analyzing them, or worse, believing them to be truths, musicians who cultivate mindfulness are often better equipped to acknowledge these thoughts, let them go, and return to the present moment.

\footnotetext{
${ }^{7}$ Gazzella, "Jon Kabat-Zinn," 62.

${ }^{8}$ Gazzella, "Jon Kabat-Zinn," 59.
} 
Definition:

"To learn about yourself, your thinking patterns, and your biases, you can engage with each moment by bringing awareness to what is happening right now."

In Being Mindful in Sport and Exercise Psychology: Pathways for Practitioners and Students, Sam Zizzi and Mark Anderson outline five components of mindfulness: “(1) presentfocused awareness, (2) an accepting and open attitude, (3) a non-judging approach, (4) compassion for self and others, and (5) energy and mindfulness." ${ }^{10}$ First, present-focused awareness encourages people to observe and understand their thought patterns, insecurities and strengths, and recognize the reality of their experiences. When people believe their thoughts and perceptions to be absolute truths, they are vulnerable to experiencing anxiety and depression. ${ }^{11}$ Second, an accepting and open attitude involves the curiosity of one's thoughts and perceptions. When people become curious about their emotions, physical sensations, and behaviors, they learn to accept whatever occurs in their minds and bodies. ${ }^{12}$ Third, Zizzi compares a non-judging approach to sitting on a riverbank and watching emotions, thoughts, and worries float by on a river. A non-judging mind is an observing mind; it acknowledges and lets go of these floating thoughts, worries, and emotions. ${ }^{13}$ Fourth, compassion for oneself and others involves the acceptance of personal failures or mistakes with understanding and empathy, instead of with anger, sadness, or disappointment. ${ }^{14}$ President Theodore Roosevelt beautifully discusses the difference between failing with resilience and compassion, and failing with insecurity and disappointment:

${ }^{9}$ Sam J. Zizzi and Mark B. Anderson, Being Mindful in Sport and Exercise Psychology: Pathways for Practitioners and Students (Morgantown: FIT Publishing 2017), 6.

10 Zizzi, Being Mindful, 6.

${ }^{11}$ Zizzi, Being Mindful, 6.

${ }^{12}$ Zizzi, Being Mindful, 7.

${ }^{13}$ Zizzi, Being Mindful, 8.

${ }^{14}$ Zizzi, Being Mindful, 9. 
It is not the critic who counts; not the man who points out how the strong man stumbles, or where the doer of deeds could have done them better. The credit belongs to the man who is actually in the arena, whose face is marred by dust and sweat and blood; who strives valiantly; who errs, who comes short again and again, because there is no effort without error and shortcoming; but who does actually strive to do the deeds; who knows great enthusiasms, the great devotions; who spends himself in a worthy cause; who at the best knows in the end the triumph of high achievement, and who at the worst, if he fails, at least fails while daring greatly, so that his place shall never be with those cold and timid souls who neither know victory nor defeat. ${ }^{15}$

Last, when individuals cultivate mindfulness, they more likely bring mindful energy into their day-to-day interactions. According to Zizzi, this mindful energy is influential on others, and can bring mindfulness to another person or a group of people. ${ }^{16}$ Rezvan Ameli, author of 25 Lessons in Mindfulness: Now Time for Healthy Living, also discusses the impact of one's mindful energy: “...It will inevitably also benefit the people who come in contact with you directly or indirectly." ${ }^{17}$ This mindful energy can be beneficial for musicians who, for example, participate in intimate chamber music settings. Entering a rehearsal room with the intention to be mindful of one's demeanor and interactions can have a positive influence on the entire chamber music group. Musicians are responsible for recognizing the energy they bring into the practice room, rehearsal room, lesson studio, and/or stage, because they are so often playing and interacting with musicians and audience members.

In Buddhist Foundations of Mindfulness, Edo Shonin, William Van Gordon, and Nirbay Singh define mindfulness by describing two of its central elements and one of its important outcomes. First, they discuss sati: "Sati involves remembering to be attentive. The opposite of sati is forgetfulness...Mindfulness has also been described as remembering where we are, what

\footnotetext{
15 “Citizenship in a Republic,” Wikipedia, last modified on January 29, 2019. https://en.wikipedia.org/wiki/Citizenship_in_a_Republic.

${ }^{16}$ Zizzi, Being Mindful, 10.

${ }^{17}$ Ameli, 25 Lessons in Mindfulness, 7.
} 
we are doing, and who we are." ${ }^{\prime 18}$ When individuals are forgetful, they often lose awareness of what they learned from the past, lose purpose in the present moment, and forget what to do in the future. The authors also discuss sampajanya: "Sampajanya involves understanding the purpose, timeliness, and suitability of what one is doing." ${ }^{19}$ Sampajanya notifies individuals when their attention or focus strays away from the present moment. One important outcome of cultivating sati and sampajanya is punya, or wisdom. Punya involves recognizing the "bigger picture" in one's life and experience, and making decisions that align with what is meaningful to him or her. $^{20}$

The definition of mindfulness includes several components. When musicians cultivate mindfulness, they not only cultivate the ability to return to the present moment, but they also develop all of mindfulness' components: awareness, acceptance, openness, compassion, curiosity, focus, and wisdom. ${ }^{21}$

Origins in Buddhism:

"The Buddha described mindfulness as the spiritual process of being fully aware of that which is, as opposed to that which was or that which might be." 22

Mindfulness originated 2,500 years ago with Buddhism. ${ }^{23}$ In Buddhism, practitioners accept suffering and emotions as natural aspects of the human experience and believe in the impermanence of all things. Impermanence focuses on the idea that emotions, thoughts, worries, physical sensations, and perceptions constantly change and/or go away. To embrace

${ }^{18}$ Edo Shonin, William Van Gordon, and Nirbay N. Singh, Buddhist Foundations of Mindfulness, (Switzerland: Springer International Publishing, 2015), 31, Springer Ebooks.

${ }^{19}$ Shonin, Buddhist Foundations, 32.

${ }^{20}$ Shonin, Buddhist Foundations, 32.

21 These components are further discussed in Chapter 2 and Chapter 3.

${ }^{22}$ Shonin, Buddhist Foundations, 2.

${ }^{23}$ Laury Rappaport, Mindfulness and the Arts Therapies: Theory and Practice, (London: Jessica Kingsley Publishers 2014), 24. 
impermanence, Buddhists practice vipassana meditations in which they mindfully acknowledge their breaths, bodies, thoughts, feelings, and actions. ${ }^{24}$ Additionally, The Four Noble Truths of Buddhism focuses on the impermanence of all things: "(1) suffering exists, (2) there is a cause of suffering, (3) there is cessation of suffering, (4) there is a path that leads to the cessation of suffering. ${ }^{25}$ The human body requires a balanced emotional, mental, and physical well-being. While we aspire to be healthy and happy, when one of these is affected (which is inevitable), a person suffers. As noted above, Buddhism accepts that suffering exists in many forms, and believes that there is a way to let go of suffering. Cultivating mindfulness helps people embrace suffering by acknowledging the nature of such negative experiences and letting them go as best as they $\mathrm{can}^{26}$

The Noble Eightfold Path of Buddhism includes eight practices that connect with mindfulness: (1) right view, (2) right intention, (3) right speech, (4) right action, (5) right livelihood, (6) right effort, (7) right mindfulness, and (8) right concentration. ${ }^{27}$ These are further separated into three categories, or trainings: (1) wisdom: right view, right intention, (2) ethics: right speech, right action, right livelihood, and (3) meditation: right effort, right mindfulness, right concentration. Although separated, these three trainings compliment and enrich one another. In Chapter 3 of Buddhist Foundations of Mindfulness, Malcolm Huxter expands on these connections:

Looking at oneself honestly (mindfulness) often requires courageous effort. The combination of effort, remembering to be attentive, and seeing deeply with focused attention gives rise to understanding. When understanding arises, this leads to right intentions, then right actions, and the path of liberation continues. In essence, this eightfactored pathway describes a process for changing or releasing unhelpful habits and

\footnotetext{
${ }^{24}$ Zizzi, Being Mindful, 18.

${ }^{25}$ Shonin, Buddhist Foundations of Mindfulness, 10.

${ }^{26}$ Shonin, Buddhist Foundations of Mindfulness, 12.

${ }^{27}$ Shonin, Buddhist Foundations of Mindfulness, 15-16.
} 
behaviors and developing, instead, what is helpful to reach desired goals that are beneficial for self and others. ${ }^{28}$

In Being Mindful, Zizzi expands on The Noble Eightfold Path's meditation training, given its strongest connection with mindfulness: right effort, right mindfulness, and right concentration. ${ }^{29}$ Right mindfulness is the awareness of internal and external surroundings, such as changing temperatures, noises, physical sensations, or thoughts. Right concentration is the deliberate attention to an object, such as the breath, a friend sharing a story, or a piece of music. Last, right effort is the exertion of energy when cultivating compassion for oneself and others, alleviating feelings of suffering, and seeing the reality of a moment. ${ }^{30}$ Although not directly related to Buddhism, Zizzi includes an old Native American adage that powerfully encapsulates right effort:

A Cherokee Elder is with his grandson, and he is trying to teach the boy some valuable lessons about living a happy life. He says to his grandson, 'There is a terrible fight happening inside of me, and it is a frightening battle between two wolves. One of the wolves is evil; he is anger, envy, sorrow, regret, greed, arrogance, self-pity, guilt, resentment, inferiority, lies, false pride, superiority, and ego. The other is good; he is joy, peace, love, hope, serenity, humility, kindness, benevolence, empathy, generosity, truth, compassion, and faith. The fight is going on inside you - and inside every other person, too.' The grandson thought about it for a minute and then asked his grandfather, 'Which wolf will win?' The old Cherokee replied, 'The one you feed. $^{31}$

Mindfulness Practice Today:

Today, many people view mindfulness as a secular practice in the West, stirring up some controversy between Buddhists and Western thinkers. In Buddhist Foundations of Mindfulness, Malcolm Huxter sheds light on the Western world's adoption of mindfulness:

\footnotetext{
${ }^{28}$ Edo Shonin, William Van Gordon, and Nirbhay N. Singh, "Mindfulness and the Buddha's Noble Eightfold Path," in Buddhist Foundations of Mindfulness, ed. Malcolm Huxter, (Switzerland: Springer International Publishing, 2015), 34.

${ }^{29}$ Zizzi, Being Mindful, 19.

${ }^{30}$ Zizzi, Being Mindful, 20.

${ }^{31}$ Zizzi, Being Mindful, 20.
} 
Long-term Buddhist meditation practitioners have mixed feelings about the popularization and commodification of mindfulness. On the one hand, we celebrate such a powerful healing tool being readily available, albeit at a price, to the world. On the other hand, some of us feel discomfort about how the public perception of mindfulness sometimes seems superficial, confused, and naive. The meaning of what is to the long-term meditation practitioner a profoundly liberating practice seems to have become diluted, obscured, and presented in a manner that is tangential to the Buddha's original descriptions. ${ }^{32}$

Controversy aside, mindfulness positively connects to social change. When we cultivate mindfulness, we become more aware, more empathetic, and more compassionate.

Mindfulness is not only understood as giving immediate practical benefits and short-term solutions to individual psychological and emotional problems - such as eating disorders, attention deficit or sexual difficulties - but it also often combined with a broader social vision and project of social emancipation and change, even freedom and revolution (i.e. practicing mindfulness to make the world a better place, such as achieving world peace, e.g.). ${ }^{33}$

What Mindfulness is Not:

"Instead of reducing or getting rid of one's discomfort, such as lowering or taking away anxiety, mindfulness allows people to increase their tolerance for or ability to be with discomfort." 34

As previously mentioned in Buddhist Foundations of Mindfulness, Huxter discusses the Western world's slightly obscured view of mindfulness. Many other misconceptions surround mindfulness today, as well. First, mindfulness does not necessarily embrace a calm and quiet mind. Sometimes, mindfulness consists of sitting with strong emotions, like anger, frustration, or disappointment. Second, meditation is not mindfulness; cultivating mindfulness enhances meditation. "You can easily just 'sit still' to escape your stressful life, and your mind can be aimlessly wandering during meditation or yoga class. ${ }^{35}$ When individuals bring mindfulness into their meditation practices, they focus on viewing themselves as witnesses to what they see,

32 Shonin, "Mindfulness and the Buddha's Noble Eightfold Path," 34.

${ }^{33}$ Shonin, Buddhist Foundations of Mindfulness, 91.

${ }^{34}$ Zizzi, Being Mindful, 32.

35 Zizzi, Being Mindful, 11. 
hear, and feel. ${ }^{36}$ Kabat-Zinn defines meditation as "the only intentional, systematic human activity, which is about not trying to improve yourself or get anywhere else, but simply realize where you already are."37 Third, practicing mindfulness is not a passive act. Mindfulness requires active awareness of thoughts, emotions, physical sensations, and behaviors. ${ }^{38}$ Fourth, mindfulness does not serve as an escape from personal issues. Mindfulness requires acknowledging and accepting present moment experiences, whether positive, negative, or neutral. ${ }^{39}$ Finally, Kabat-Zinn discusses that mindfulness does not require awareness of every single moment: "There are many interesting, technical questions about how to become more mindful, but I want to emphasize that becoming even a tiny bit more mindful is good. You do not have to be totally mindful at every hour of the day and night. That is merely an ideal.. ${ }^{, 40}$

Mindfulness embraces one's present moment experience, whether positive, negative, or neutral, requires active participation, is not strictly tied with meditation, and does not require constant awareness. If musicians recognize these misconceptions, they may more likely invite mindfulness during high stress, anxiety-ridden practice sessions, rehearsals, and performances when their minds are lost in thought, worry, or emotion.

Mindfulness in Western Medicine:

"We need to know more about the science of compassion, the science of empathy, the science of acceptance, as well as the art of compassion, the art of empathy, the art of acceptance." 41

Due to its physical, mental, and emotional benefits, such as lower blood pressure, improved immune system response, improved psychological health, decreased neuroticism,

\footnotetext{
${ }^{36}$ Kabat-Zinn, Wherever You Go, 11

${ }^{37}$ Kabat-Zinn, Wherever You Go, 14

${ }^{38}$ Zizzi, Being Mindful, 11.

${ }^{39}$ Zizzi, Being Mindful, 11.

${ }^{40}$ Gazzella, "Jon Kabat-Zinn," 62.

${ }^{41}$ Gazzella, "Jon Kabat-Zinn," 64.
} 
improved self-regard, and higher satisfaction with life, Kabat-Zinn integrated mindfulness into Western medicine in the late 1970s. ${ }^{42}$ Kabat-Zinn studied molecular biology at the Massachusetts Institute of Technology (MIT) during the 1960s, and was highly interested in human beings' nervous systems. One particular lecture at MIT by Philip Kapleau, teacher of Zen Buddhism and author of The Three Pillars of Zen, cemented his interest in human beings' nervous systems, and sparked his interest in mindfulness. ${ }^{43}$ Kabat-Zinn reflects on his thoughts after he attended Kapleau's inspiring lecture:

The laboratory of your own life may be at least as valid to look at as the laboratory of other people's brains or nervous systems, or as designing experiments in the lab to test one thing or another, which is a third-person orientation. But the first-person orientation is, 'Who am I?' Why not bring scientific rigor to that kind of inquiry? Why not use all the instruments at our disposal —our multiple senses? I would say there are more than five of them-including the capacity to refine awareness. Perhaps we can then find a way to come to some kind of greater integrity and balance in our lives. So it's not just about accomplishing great things and pushing back the frontiers of science, but also living your own life with a degree of balance and well-being that might influence not only physical health, but also mental and spiritual health. ${ }^{44}$

Years later, Kabat-Zinn attended a Buddhist meditation retreat. Attending the retreat motivated him to share meditation and mindfulness practices with populations that do not typically attend Buddhist retreats. In 1979, Kabat-Zinn established Mindfulness-based Stress Reduction (MBSR). ${ }^{45}$ MBSR was the first program that "brought an Eastern philosophical concept of mindfulness into Western medicine and psychotherapy.. ${ }^{, 46}$ This program pairs with traditional medical practices, and incorporates exercises that nurture and cultivate one's awareness of thoughts, physical sensations, emotions, and behaviors. ${ }^{47}$ MBSR utilizes

\footnotetext{
${ }^{42}$ Lecuona de la Cruz, "Mindfulness and Music," 28.

${ }^{43}$ Gazzella, "Jon Kabat-Zinn," 58.

${ }^{44}$ Gazzella, "Jon Kabat-Zinn," 58.

${ }^{45}$ Zizzi, Being Mindful, 25.

${ }^{46}$ Zizzi, Being Mindful, 25.

${ }^{47}$ Zizzi, Being Mindful, 25.
} 
mindfulness to reduce stress, suffering, improve one's psychological health, and is designed for patients with chronic pain, arthritis, cancer, and psoriasis. ${ }^{48}$ For example, Kabat-Zinn discovered that "people with psoriasis who meditate while receiving ultraviolet treatments heal at four times the rate of control subjects who get only the light." ${ }^{49}$ Since MBSR's inception, thousands of people have improved their psychological and physical health by integrating mindfulness into their daily lives. Additionally, research on mindfulness-based therapies has expanded and other mindfulness-based therapies have developed since the $1970 \mathrm{~s}^{50}$

Examples of these related mindfulness-based therapies are Mindfulness-based Cognitive Therapy (MBCT), and the Mindfulness-Acceptance-Commitment (MAC) model. Psychologists Zindel Segal, Mark Williams, and John Teasdale developed MBCT. MBCT adopts elements of Kabat-Zinn's MBSR therapy and elements of cognitive behavioral therapy, and is designed for individuals with depression, anxiety, social anxiety, bipolar disorder, and panic disorder. ${ }^{51}$ For example, implementing MBCT for individuals with depression encourages them to understand what specific elements in their lives cause their bouts of depression. ${ }^{52}$

Sport psychologists Frank Gardner and Zella Moore developed the MindfulnessAcceptance-Commitment (MAC) model. This model combines elements of Acceptance and Commitment Therapy (ACT) and $\mathrm{MBCT}{ }^{53} \mathrm{ACT}$ aims to reduce unnecessary suffering through

${ }^{48}$ Lecuona de la Cruz "Mindfulness and Music," 27.

${ }^{49}$ Gazzella, "Jon Kabat-Zinn," 63.

${ }^{50}$ Shonin, Buddhist Foundations of Mindfulness, 29.

51 “About MBCT," MBCT, accessed February 27, 2019, http://www.mbct.com/about-mbct.html. Also discussed in Lecuona de La Cruz, "Mindfulness and Music," 28.

52 "How will mindfulness practice help me," MBCT, accessed February 27, 2019, http://www.mbct.com/how-will-mindfulness-practice-help-me.html.

${ }^{53}$ ACT is further discussed in Chapter 3. 
acceptance, values-based behaviors, and committed action. ${ }^{54}$ The MAC model is very similar to ACT, but also integrates mindfulness, embraces a non-judging awareness of the present moment, and specifically targets athletes. ${ }^{55}$ Although the MAC model is designed for athletes, musicians can reinterpret its phases. The MAC model includes five phases:

Phase \#1, Educational Phase: A discussion between the therapist and the athletes occurs to gain an understanding of what external and internal events lead to difficulties in their performances.

Phase \#2, Mindfulness Phase: Mindfulness techniques are taught to improve awareness of internal experiences, and to develop a non-judging awareness of the present moment. Emphasis is placed on acknowledging and letting go of thoughts and worries, and not viewing them as absolute truths. To cultivate mindfulness, athletes are taught situational refocusing exercises to practice in therapy sessions, at home, and during practices and performances. These exercises encourage the athletes to practice awareness of their thoughts and worries, and to return to the present moment as much as possible.

Phase \#3, Values Identification and Commitment Phase: This phase focuses on defining and distinguishing personal goals (outcome-oriented) and values (process-oriented). Defining values encourages the athletes to connect their actions with their values, regardless of any external or internal experiences that occur during practices or performances.

Phase \#4, Acceptance Phase: The athletes learn to accept their thoughts, emotions, and situations, instead of controlling these experiences, or seeing them as absolute truths. This phase encourages the athletes to find connections between their thoughts, emotions,

\footnotetext{
${ }^{54}$ Frank Gardner and Zella E. Moore, "Mindfulness-Acceptance-Commitment (MAC) for Performance Development (PD)," in Clinical Sport Psychology (Champaign: Human Kinetics, 2006), 102. Also discussed in Zizzi, Being Mindful, 26.

${ }^{55}$ Gardner, "Mindfulness-Acceptance-Commitment (MAC)," 103.
} 
and behaviors, and understand how these connections relate to specific performance experiences and outcomes. ${ }^{56}$

Phase \#5, Integration: The final phase encourages the athletes to practice and cultivate these mindfulness, acceptance, and commitment skills by incorporating them into their everyday lives: "Finally, special attention is given to continually using these new skills in practice and competition, as well as in relevant nonathletic situations." ${ }^{, 57}$

Although the MAC model applies to athletes, the model appears to have relevance to musicians due to the similar physical, mental, and emotional demands surrounding training and performances. Musicians can reinterpret and adopt the MAC model's five phases for their practice sessions, rehearsals, performances, and everyday lives.

Chapter 2: Mindfulness and Emotions

When preparing for a high stress event, such as an audition or a solo recital, musicians may experience intense emotions, such as panic or anxiety, prior to and during the event. These intense emotions may hijack musicians' minds and affect their mental and physical states while practicing, rehearsing and performing. Understanding physiological responses to intense emotions like anxiety, fear, panic, and worry, may help musicians cope with these experiences when they arise. ${ }^{58}$ Jeffrey Brantley, author of Calming Your Anxious Mind: How Mindfulness and Compassion Can Free You from Anxiety, Fear, and Panic, emphasizes that "physical experience is deeply interconnected with psychological and emotional experiences... ${ }^{, 59}$ Brantley encourages his readers to understand how intense emotions like fear, worry, anxiety, and panic

\footnotetext{
${ }^{56}$ Gardner, "Mindfulness-Acceptance-Commitment (MAC)," 104.

${ }^{57}$ Gardner, "Mindfulness-Acceptance-Commitment (MAC)," 105.

${ }^{58}$ A physiological response is an automatic, instinctive reaction that produces a physical response.

${ }^{59}$ Brantley, Calming Your Anxious Mind, 13.
} 
manifest physiologically in their bodies. Descriptions of the definitions, causes, and physiological responses of these emotions are included below.

Fear: Fear produces feelings of dread, foreboding, and terror. The cause of fear is a presence or a near presence of an identified danger or threat. Its physiological responses may consist of feelings of agitation, nausea, a pounding heart, sweating, and trembling.

Anxiety: Anxiety produces feelings of dread and foreboding. Due to no tangible presence of an identified danger or threat, anxiety is an irrational fear. Its physiological responses may consist of feelings of agitation, nausea, physical and mental distress felt deeply in the mind and body, a racing heart, chest pain or discomfort, and dizziness.

Panic: Panic produces a feeling of intense, sudden, and overwhelming fear. Panic's cause is similar to anxiety's cause: an irrational fear due to no tangible presence of an identified danger or threat. Its physiological responses may consist of tingling sensations or numbness experienced in the body, nausea, difficulty breathing, chest pain or discomfort, and dizziness.

Worry: Worry produces racing thoughts, stories, and images of future or past events. Worry is the "mind's expression of anxiety." ${ }^{\circ 0}$ Its physiological responses may combine the physiological responses of anxiety with thoughts, stories, and images that enhance the anxiety. ${ }^{61}$

Practicing mindfulness can help musicians better understand how their bodies respond to a specific emotion during high stress events. For example, before musicians realize how anxious and worrisome they are, they may recognize that they are not breathing with their entire bellies, or notice tightness in their chests. Conversely, if musicians suppress their emotions, do not

\footnotetext{
${ }^{60}$ Brantley, Calming Your Anxious Mind, 15.

${ }^{61}$ Brantley, Calming Your Anxious Mind, 15-16.
} 
mindfully acknowledge them, and/or allow them to hijack their minds and bodies, anxiety disorders may develop, and they may adopt unwise emotional responses, such as avoidance or elaborate rituals. ${ }^{62}$ When becoming mindfully aware of their physiological responses to intense emotions, musicians can appropriately find ways to cope with these emotions before they become chronic.

Brantley reinforces that everyone experiences panic, worry, fear, and anxiety, and that normal doses of these emotions are helpful. For example, helpful doses of anxiety improve focus and strengthen productivity. ${ }^{63}$ However, when these emotions become chronic, they change from helpful to debilitating: "When the fear reaction arises repeatedly and persists over time, it is called chronic. We could say that to call fear or anxiety chronic means that it is a frequent visitor to the present moment. Chronic fear and anxiety can affect your relationships, work, social life, personal health, and inner life." ${ }^{64}$ Chronic anxiety can manifest in the following nine ways: restlessness, fatigue, disrupted sleep, faltering concentration, a blank mind, avoidance of social situations, irritability, elaborate rituals and/or compulsions, and higher use of substances (alcohol or drugs, for example). ${ }^{65}$

In addition to understanding one's physiological responses, Brantley also includes ways to cope with these intense emotions in order to better control one's reaction to these experiences. First, he discusses that some individuals may benefit from medication or therapy, especially if the anxiety is severely chronic or inherited. ${ }^{66}$ Types of therapies that embrace mindfulness and

\footnotetext{
${ }^{62}$ Orsillo, Acceptance and Mindfulness-based Approaches, 52.

${ }^{63}$ Brantley, Calming Your Anxious Mind, 17.

${ }^{64}$ Brantley, Calming Your Anxious Mind, 17.

${ }^{65}$ Brantley, Calming Your Anxious Mind, 17.

${ }^{66}$ Brantley, Calming Your Anxious Mind, 20.
} 
reduce anxiety are MBSR and MBCT, which are discussed in Chapter $1 .{ }^{67}$ Second, because fear, anxiety, worry, and panic thrive on thoughts of the future or the past, Brantley encourages his readers to stay in the present moment: "As you increasingly come to see these experiences as conditions in the present moment instead of as your enemy or your 'problem,' they will no longer dominate your life. You will make more effective responses to them." ${ }^{68}$ Finally, cultivating mindfulness as a lifestyle encourages individuals to return to the present moment in order to gain perspective, take a breath, and respond wisely. ${ }^{69}$ Brantley eloquently writes about the benefits of living with mindfulness in one's everyday life:

This approach to fear, anxiety, and panic works best when you make mindfulness a way of living. To approach life mindfully is to meet and connect with each experience as it arises and flows through the present moment of life. Mindfulness will not work so well if you think of it as a method or technique and wait to use it only when fear, anxiety, or panic is here and troubling you. Mindfulness becomes a way of living when you ground it in a daily practice of meditation and extend this practice into your life. $^{70}$

Mindfulness can help musicians recognize their physiological responses to intense emotions, such as fear, panic, worry, and anxiety during practice sessions, rehearsals, and performances. When musicians mindfully recognize their physiological responses to these emotions, they learn how to cultivate awareness of these experiences, gain some perspective, respond wisely, and return to the present moment. ${ }^{71}$

\footnotetext{
${ }^{67}$ Brantley, Calming Your Anxious Mind, 21.

${ }^{68}$ Brantley, Calming Your Anxious Mind, 25.

${ }^{69}$ Methods on how to stay in the present moment and understanding factors that "get in the way" of staying in the present moment are discussed in Chapter 3.

${ }^{70}$ Brantley, Calming Your Anxious Mind, 26.

${ }^{71}$ Susan M. Orsillo and Lizabeth Roemer, Acceptance and Mindfulness-based Approaches to Anxiety: Conceptualization and Treatment (New York: Springer, 2005), 52, Springer Ebooks.
} 
Chapter 3: Being in the Present Moment

Don Greene is a sport psychologist who offers peak performance training to world-class musicians and Olympic athletes. His trainings impact many people, such as Noa Kageyama, creator of The Bulletproof Musician, an online platform and course that helps musicians achieve peak performance more consistently. ${ }^{72}$ In Greene's book, Performance Success: Performing Your Best Under Pressure, he relates returning to the present moment during a performance to baby-sitting a toddler:

Imagine baby-sitting an active toddler, and trying to get her to stay within a three-foot circle for more than a few seconds. The child will stand still for only a moment before leaving to pursue something of interest. After the child is out of the circle, if you yell and find fault with her for not staying in the circle, she will run in any direction other than towards the circle.

When you are performing, if you are thinking about what someone else may be thinking, you are outside the circle. If you are worried about making a mistake or thinking about the ultimate results of your performance or about what you might do afterwards, you are outside your circle. If you then find fault with yourself for not concentrating, you're making matters worse. You're moving farther away from being focused. The idea is to gently guide your attention, like you would the child, back on point.

You need to get back inside the circle, which represents your process, as soon as possible. Do not waste valuable time and energy criticizing yourself; just get back to the here and now as soon as possible. You can learn to do this faster and better; all it takes is practice and energy. ${ }^{73}$

Staying in the present moment requires deliberate participation, dedication, and practice, just like baby-sitting a toddler. Cultivating mindfulness helps musicians actively return to the present moment, and does not allow their minds and bodies to go on autopilot: "Autopilot is what happens when we've done something, like walk, drive, or do the dishes, so many times we

\footnotetext{
72 Peak performance is a subjective state of confidence, effortlessness, and complete focus.

${ }^{73}$ Don Greene, Performance Success: Performing Your Best Under Pressure (London: Routledge, 2001), 81-82.
} 
don't need to focus on it anymore with mindful attention. ${ }^{, 74}$ Because people go on autopilot during these experiences, they start to multitask: driving while talking on the phone, folding laundry while reading a chapter for class, walking to class while planning a practice schedule, etc. When musicians multitask while driving or doing the dishes, multitasking may infiltrate into their practice sessions, rehearsals, and performances. Although multitasking is often praised in society, it is incredibly inefficient, and moves people away from the present moment. ${ }^{75}$ For example, while practicing a musical passage, one's mind may plan what to work on in the next practice session, or plan what to wear for a performance later that evening.

In Make Peace With Your Mind: How Mindfulness and Compassion Can Free Your Inner Critic, Mark Coleman writes about the negative effects of multitasking: "Research shows that multitasking on the job diminishes both our efficiency and the quality of our work. Even worse, multitasking releases stress hormones cortisol and adrenaline, which can lead to all kinds of health problems. ${ }^{, 76}$ By committing to one task at a time, musicians gain the ability to contact the present moment more frequently, and mindfully become aware of their actions, thoughts, emotions, and behaviors.

When embracing their present moment experiences, musicians do not focus on fleeting thoughts, worries, and emotions, but focus on their technical and musical demands, ideal for practice sessions and performances. The following seven sections of this chapter include specific skills and methods that help musicians more readily contact the present moment, a crucial component of mindfulness and a helpful skill for their training. The seven sections are: (1) psychological flexibility, (2) psychological flexibility and ACT for musicians, (3) the inner

\footnotetext{
${ }^{74}$ Mark Coleman, Make Peace With Your Mind: How Mindfulness and Compassion Can Free Your Inner Critic (Novato, California: New World Library, 2016), 110.

${ }^{75}$ Coleman, Make Peace With Your Mind, 111.

${ }^{76}$ Coleman, Make Peace With Your Mind, 111.
} 
critic, (4) acceptance, (5) perfectionism, (6) experiencing flow, and (7) musicians in the present moment.

Psychological Flexibility:

"Psychological flexibility is the ability to contact the present moment more fully as a conscious human being. ",77

Developing psychological flexibility helps musicians let go of thoughts, worries, and physical sensations while practicing and performing, and return to the present moment. Staying in the present moment serves as a crucial skill for musicians; it encourages them to focus entirely on their playing capabilities instead of their thoughts, worries, and perceptions. Embracing elements of Acceptance and Commitment Therapy (ACT) helps individuals cultivate psychological flexibility. Six elements of ACT are (1) acceptance, (2) cognitive defusion, (3) sense of self, (4) contact with the present moment, (5) defined values, and (6) committed action. $^{78}$

Acceptance is not the act of giving up, but growing aware of one's reality and embracing his or her experience. ${ }^{79}$ Cognitive defusion focuses on defusing one's reaction to emotions, thoughts and physical sensations, and viewing these experiences as momentary." ${ }^{80}$ Sense of self involves embracing one's experience in the "here and now" instead of in the "there and then." Individuals typically associate their identities with past events, recurring events, or other people's perceptions of them, instead of embracing their identities and experiences in the present moment. Susan Orsillo, author of Acceptance and Mindfulness-based Approaches to Anxiety: Conceptualization and Treatment reminds her readers that their past experiences, emotions, and

${ }^{77}$ Orsillo, Acceptance and Mindfulness-based Approaches, 108.

${ }^{78}$ Orsillo, Acceptance and Mindfulness-based Approaches, 108.

${ }^{79}$ Orsillo, Acceptance and Mindfulness-based Approaches, 109.

${ }^{80}$ Orsillo, Acceptance and Mindfulness-based Approaches, 111. 
thoughts do not define them: "Anxiety, panic, intrusive thoughts, or worry are things they sometimes have and sometimes do not. They are experiences that are felt, not identifying characteristics. ${ }^{\prime 81}$ Contact with the present moment embraces sense of self because it encourages people to accept their experiences, defuse their reactions, and not identify with their past experiences. ${ }^{82}$ Defined values helps individuals make wise, informed decisions when they are thrown from the present moment due to thoughts, worries, and ruminations. Values, unlike goals, can never be achieved, and offer direction and guidance to one's actions. ${ }^{83}$

Finally, when these elements are considered and practiced, taking committed action encourages individuals to accept their experiences and follow through with the tasks they value, instead of avoiding their experiences and not taking action: "The process of avoiding something reinforces the verbal processes that cause the event to be experienced as aversive. It strengthens those relational frames. Thus, the event will continue to be experienced as aversive and anxiety producing. It gets worse not better." 84

ACT develops psychological flexibility due to its focus on accepting one's present moment experience, defusing one's reaction to the experience, not identifying with past events, deliberately contacting the present moment, returning to his or her defined values, and taking committed action. Developing psychological flexibility encourages musicians to wisely respond to their present moment experiences, a helpful tool for high stress performance situations. Psychological Flexibility and ACT for Musicians:

Psychological flexibility and elements of ACT embrace mindfulness because they emphasize the importance of the present moment and recognize that all thoughts, emotions, and

${ }^{81}$ Orsillo, Acceptance and Mindfulness-based Approaches, 112.

${ }^{82}$ Orsillo, Acceptance and Mindfulness-based Approaches, 112.

${ }^{83}$ Orsillo, Acceptance and Mindfulness-based Approaches, 113.

${ }^{84}$ Orsillo, Acceptance and Mindfulness-based Approaches, 106. 
physical sensations as momentary. Musicians can benefit from cultivating mindfulness and developing psychological flexibility by adopting elements of ACT to their daily routines:

Acceptance: Before a performance, lesson, or rehearsal, musicians can accept their playing level, preparation, and present moment experience. Acceptance reminds musicians that they cannot change their present moment situations immediately before walking out on stage or entering the classroom.

Cognitive defusion: While performing, thoughts and worries sometimes infiltrate musicians' minds: "Oh no! The hard part is coming up," "I can't believe I missed that high note," "I don't belong on stage with these amazing musicians," or "I feel tired." Instead of viewing these thoughts and worries as truths, cognitive defusion encourages musicians to simply view their thoughts as thoughts and worries as worries, and let them pass. If musicians choose to dwell on these experiences, they may lack sufficient control of their reactions and actions.

Sense of self: Many musicians attach their self-worth to specific past experiences: "I started private lessons much later than my peers," "My high school music teacher told me I couldn't become a professional musician... maybe she's right," or "I am a nervous performer - remember when my completely blanked during my freshman year jury?" Sense of self encourages musicians to identify themselves with the present moment and not with past experiences:

Nothing is actually stopping the person from moving ahead; moving ahead is stopped by the person's own verbal behavior. The person might be right - the traumatic event as a child contributed to his or her struggle with anxiety, but that does not mean that that event or memory must be corrected before one can change his or her behavior. ACT assumes that the person can move ahead just as he or she is, no change in 'self' is needed. ${ }^{85}$

${ }^{85}$ Orsillo, Acceptance and Mindfulness-based Approaches, 112. 
Contact with the present moment: While practicing, rehearsing, or performing, arising thoughts, emotions, worries, and physical sensations are inevitable. Contact with the present moment encourages musicians to acknowledge when these experiences arise, and then choose to stay in the present moment instead of feeding these experiences. When musicians make contact with the present moment during these events, they are able to experience the practice session, rehearsal, or performance as it is, instead of through their perceived thoughts and perceptions.

Defined values: When musicians define their values, they recognize why they react a certain way to an experience, how they find motivation when experiencing burnout or intense anxiety, and how to cope with difficult experiences that take them away from the present moment. ${ }^{86}$ Below are two brief examples of two musicians' defined values:

Value \#1, respect for the performer, speaker, or lecturer: When Rose attends a performance, a lecture, or even a class, she turns off her cell phone, does not bring food into the venue, stays quiet throughout the whole performance, and claps when the performers or speakers finish their performance. Therefore, when she performs and hears a candy wrapper, a whisper, or a cell phone ring in the audience, she is immediately distracted not only by the noise itself, but also by her thoughts: “The nerve! I can't believe that person didn't turn their cell phone off!" Why do you need to have a butterscotch candy during the quietest moment of the piece?" or "Can't you keep your comments and questions to yourself for just five more minutes?" These thoughts, although aligned with her values, take her away from the present moment. After realizing this, Rose acknowledges that respecting performers is not everyone's defined value. Therefore, when she hears yet

\footnotetext{
${ }^{86}$ Burnout is further discussed in Chapter 4.
} 
another cell phone ring during a performance, she acknowledges her thoughts, lets them go, and returns to the task at hand.

Value \#2, improving on piano to become a better piano teacher: A couple of times a year, Leo experiences burnout. When he experiences burnout, he feels irritable, his practice and rehearsal sessions feel unproductive, and his performances feel uninspired. Sometimes, if the burnout feels particularly severe, he questions if he can really commit to a music career for his entire life. When he experiences this intense burnout, he reflects on his defined value: to grow and improve as a pianist so he can effectively teach and guide his students. When Leo moves his personal progress away from himself and attaches his progress to this value, he grows inspired, motivated, and committed to his improvement as a pianist.

Committed action: Musicians invest a lot of energy into worrying, ruminating, panicking, and planning while playing their instruments. Instead of investing their energy in these experiences, they can direct that same energy into actions that move them closer to their values. For example, worrying about an upcoming performance takes away from the energy a musician can place into the practice session or rehearsal that will prepare him or her for the performance.

Reacting to negative experiences, worrying about uncertain events, and ruminating about past mistakes distracts musicians from contacting the present moment. Employing elements of ACT into their everyday lives assists musicians in developing psychological flexibility, and the ability to more readily contact the present moment. 
The Inner Critic:

"Have you been more motivated and inspired in your life when you were encouraged, supported and challenged or when you were criticized, judged and threatened? ",87

While practicing or rehearsing, musicians critique and evaluate themselves with the intention to improve. At times, their inner critic can be helpful during practice sessions, rehearsals, and performances. However, their inner critic becomes unproductive and unhelpful when it attacks their self-worth, instead of objectively identifying technical issues or discrepancies. To diminish the inner critic's attacks, Coleman, author of Make Peace With Your Mind, encourages his readers to practice discernment instead of judgment. Discernment is associated with a clear, open-minded perspective while judgment is associated with reactivity, a close-minded perspective, and not being able to focus on the big picture. ${ }^{88}$ Below is a brief example of a musician practicing judgment and discernment.

Carmen is an undergraduate cello performance and music education major with a twentycredit semester load and a part-time job. She is currently preparing for her junior cello recital, but has difficulty finding practice time in her busy schedule, and consistently feels unprepared for lessons. A few weeks into the semester, Carmen performs in cello studio class where her colleagues perform pieces they are preparing for juries and recitals. Unfortunately, her performance goes very poorly. She misses multiple shifts, her double-stops are out of tune, and she starts over in one section because she and her pianist were drastically off from one another. Following the disappointing performance, Carmen's inner critic judges her playing and her selfworth: "You will never be prepared for this recital, so why bother even practicing?" "You are an

${ }^{87}$ Jim Loehr and Tony Schwartz, The Power of Full Engagement: Managing Energy, Not Time, Is the Key to High Performance and Personal Renewal (New York: The Free Press, 2003), 76. ${ }^{88}$ Coleman, Make Peace With Your Mind, 56. 
awful musician and performer," and "Even if you pull off this recital, you won't be able to play these pieces as beautifully as your colleagues."

Now, imagine the same scenario. However, after the performance, Carmen's inner critic practices discernment instead of judgment. Immediately after she plays, Carmen reflects on the less successful sections of the performance so she knows what to prioritize in her practice sessions next week. Following this self-reflective practice, Carmen evaluates why she had a poor performance by noting the reasons that likely prevented her from feeling prepared. She identifies the following three reasons: (1) poor sleep the night before due to a deadline for an assignment, (2) lack of practice time due to a busy schedule, and (3) inadequate rehearsal time with the pianist. She realizes she cannot change her workload and schedule, but she can prioritize sleep, prioritize the less successful sections in her practice sessions next week, and try to find another thirty-minute time slot in her schedule to rehearse with her pianist. Last, Carmen decides to talk to her professor for advice on how to fit practice sessions into her busy schedule.

When being judgmental, Carmen's inner critic does not offer a solution to her poor performance, attacks her self-worth, and prevents her from thinking objectively after the performance. When practicing discernment, Carmen still recognizes and accepts her poor performance, but instead of attacking her self-worth, she objectively states the reasons that caused the poor performance, and explores ways to improve her practice and rehearsal schedules. Coleman discusses the beneficial results of practicing discernment instead of judgment:

There are far more kind, considerate, and inspiring ways to motivate ourselves than the bullwhip or the shaming stick. Numerous management studies show that people are far more motivated and engaged when inspired by a leader who is encouraging, positive, and focused on what is possible rather than on faults or foibles. What we need is to stay connected with what gives us meaning, purpose, and value. We need to orient ourselves toward all that is possible rather than fixate on the critic's negative scenarios. ${ }^{89}$

${ }^{89}$ Coleman, Make Peace With Your Mind, 54. 
Unfortunately, many musicians believe that judgment is simply a part of the profession. Perhaps this belief can be challenged. Coleman shares a story about a woman who is an actor and theater director in New York City. This woman incessantly judges herself, views judgment as a crucial element of an actor's life, and believes that as an actor, you "get used to it (judgment)." However, after working closely with Coleman, she realizes that no one grows accustomed to that annoying voice inside of their heads, because if they did, they would be able to turn that voice off. She understands that her judgments are merely thoughts and they have nothing to do with her acting and directing capabilities. ${ }^{90}$

In addition to practicing discernment, another way to quiet the inner critic is to practice mindfulness. Mindfulness offers clarity, awareness, and a choice on how to respond to an experience, thought, or emotion. ${ }^{91}$ Cultivating mindfulness embraces discernment because one learns to gain perspective on a thought or experience, finds clarity, and chooses how to thoughtfully respond. Coleman expands on the benefits of cultivating mindfulness in order to quiet the inner critic:

Mindfulness helps you become acutely aware of your thoughts - the good, the bad, and the ugly... without awareness there's no possibility of a different course of action. When we see the painfulness of our judgments clearly, we see that we have a choice, and we can begin to develop strategies to diminish their influence over us...It helps you discern what is healthy and helpful and what is not... With the ability to discern, you can choose to ignore the critic and shift your attention to something more constructive. ${ }^{92}$

One final way of quieting the inner critic is to identify the inner critic's voice. For example, the inner critic's voice can be a parent, a sibling, or a past teacher. If individuals have difficulty identifying their inner critic's voice with a specific person, Coleman encourages his readers to reflect on the environment they grew up in: "Children are sponges and soak up the

${ }^{90}$ Coleman, Make Peace With Your Mind, 121.

${ }^{91}$ Coleman, Make Peace With Your Mind, 119.

${ }^{92}$ Coleman, Make Peace With Your Mind, 120. 
atmosphere they are in. They often pick up the way parents treat themselves." ${ }^{93}$ Identifying the inner critic's voice brings an individual closer to practicing discernment and mindfully responding to the inner critic's judgments.

One's inner critic is unhelpful when it negatively critiques and evaluates his or her selfworth. Practicing discernment instead of judgment, cultivating mindfulness, and identifying the inner critic's voice encourages musicians to quiet their unhelpful, harsh inner critics during practice sessions, rehearsals, and performances.

Acceptance:

"Acceptance should not be confused with tolerance or resignation, both of which are passive and fatalistic. Acceptance involves awareness and the active embrace of private experiences, as they are, not as what they say they are." 94

As previously discussed in the section on psychological flexibility, acceptance focuses on "the willingness to see things exactly as they are in the present moment." 95 Sometimes, when people cultivate mindfulness and awareness of their present moment, they must experience and accept intense emotions like anger or fear, for example. In Calming Your Anxious Mind, Brantley writes: "Acceptance does not mean you have to like everything...(have) a passive attitude...be satisfied with things as they are, or that you have to stop trying to change things for the better." 96 When individuals accept their present moment's reality, they act on their emotions, thoughts, and experiences in a constructive manner, whether that is sitting with the experience, changing the experience, or improving the experience. ${ }^{97}$

${ }^{93}$ Coleman, Make Peace With Your Mind, 133.

${ }_{94}$ Orsillo, Acceptance and Mindfulness-based Approaches, 109.

${ }^{95}$ Brantley, Calming Your Anxious Mind, 81.

${ }^{96}$ Brantley, Calming Your Anxious Mind, 81.

${ }^{97}$ Brantley, Calming Your Anxious Mind, 81. 
Embracing acceptance is not only valuable for musicians prior to a performance, but also during a performance when things do not always go as planned. In his book Performance Success: Performing Your Best Under Pressure, Greene discusses how acceptance helps you return to the present moment during a performance:

Accept the mistake as soon as possible: Denial is time-consuming and does not serve one's mind during performances (ex; "I cannot believe I just missed that note! or "I cannot believe I counted incorrectly in this passage - I usually always count correctly!’).

Return to the present moment: Allowing one's mind to analyze and dwell on the mistake takes him or her further from the present moment.

Relax muscles: Use the mistake as an opportunity to relax tension in one's muscles (ex; violinists can relax their shoulders).

Set an intention: "Stay with the music," "Keep it rolling," "Be in the present moment," or "Return to the present moment." Use these phrases as cues to return to the present moment. Before a performance, define which intention will serve as your cue to contact the present moment. ${ }^{98}$

In Performance Success, Greene presents an effective method of employing acceptance during performances. When embracing acceptance during practice sessions, rehearsals, performances, musicians accept their present moment experiences, and return to the task at hand more quickly.

${ }^{98}$ Greene, Performance Success, 91-92. 


\section{Perfectionism:}

"Our imperfections are not inadequacies, they are reminders that we are all in this together. Imperfectly, but together." 99

Another way to calm the inner critic is to let go of perfectionism. Perfectionism inhibits people from personal growth, vulnerability, and acceptance. Brene Brown, shame and fear-based Research Professor at the University of Houston Graduate College of Social Work, identifies two common myths surrounding perfectionism:

1. Perfectionism is not the same thing as striving to be your best...Perfectionism is the belief that if we live perfect, look perfect, and act perfect, we can minimize or avoid the pain of blame, judgment, and shame. It's a shield.

2. Perfectionism is not self-improvement. Perfectionism is, at its core, about trying to earn approval and acceptance. Most perfectionists were raised being praised for achievements and performances (grades, manners, rule-following, people-pleasing, appearance, sports)...we adopt this dangerous and debilitating belief system: I am what I accomplish. ${ }^{100}$

Research shows that perfectionism actually inhibits success and leads to non-desirable

mental states like depression, anxiety, addiction, and avoidance. ${ }^{101}$ Brown discusses three negative results of perfectionism:

1. Perfectionism is self-destructive simply because there is no such thing as perfect...Additionally, perfectionism is more about perception - we want to be perceived as perfect...this is unattainable - there is no way to control perception. 2. Perfectionism is addictive because when we do experience shame, judgment, and blame, we often believe it's because we weren't perfect enough.

3. Feeling shamed, judged, and blamed (and the fear of these feelings) are realities of the human experience. Perfectionism actually increases the odds that we'll experience these painful emotions and often leads to self-blame: It's my fault. I'm feeling this way because 'I'm not good enough. '102

${ }^{99}$ Brene Brown, Gifts of Imperfection: Let Go of Who You Think You're Supposed to Be and Embrace Who You Are (Center City: Hazelden Publishing, 2010), 61.

${ }^{100}$ Brown, Gifts of Imperfection, 56.

${ }^{101}$ Brown, Gifts of Imperfection, 56.

${ }^{102}$ Brown, Gifts of Imperfection, 57. 
Many musicians adopt perfectionism because they aim to play pieces with perfectly accurate rhythm, intonation, pulse, character, etc. Because perfectionism produces negative results, how can musicians overcome perfectionism? Brown encourages her readers to "embrace imperfections" and alter their inner dialogue when trying to accomplish a task. ${ }^{103}$ She discusses that individuals must adopt healthy-striving self-talk instead of perfectionism self-talk to challenge perfectionism. ${ }^{104}$ Instead of asking, "What will they think?" healthy-striving self-talk asks, “How can I improve?" Below are two brief examples of perfectionism self-talk and healthy-striving self-talk:

Perfectionism self-talk: Oh no! I messed up that passage again! I'm so stupid. How could I let that happen yet another time? I wonder what my colleagues and teachers thought about my performance? I need to improve this passage right now to be worthy of praise and respect from my colleagues and teachers.

Healthy-striving self-talk: I rushed these fast notes, and I missed a high note at the end of this passage. Perhaps I can approach this passage differently in the practice room by playing it slowly for a while? I want to improve this passage to feel more secure when I perform this piece.

First, when comparing these self-talks, perfectionism self-talk berates the musician, does not objectively identify what can be improved in the passage, and wants to improve the passage only to avoid disrespect and embarrassment from colleagues and teachers. In the healthy-striving self-talk, the musician objectively identifies what can be improved in the passage, tries to find a different approach in practicing the passage, and wants to improve the passage to feel more secure while performing the piece. Second, the perfectionism self-talk focuses on the perception

\footnotetext{
${ }^{103}$ Brown, Gifts of Imperfection, 57.

${ }^{104}$ Brown, Gifts of Imperfection, 58.
} 
of others and uses words like "need," while the healthy-striving self-talk focuses on personal growth and uses words like "want." Finally, the healthy-striving self-talk does not sugarcoat unsuccessful situations, but identifies the issues and aims to improve them. ${ }^{105}$

In addition to understanding perfectionism's roots and adopting healthy-striving self-talk, one can also alleviate perfectionism through a loving-kindness meditation. ${ }^{106}$ Loving-kindness meditations alleviate feelings of inadequacy or "not good enough." Below is an example of a loving-kindness meditation from Kabat-Zinn's book, Wherever You Go, There You Are:

Start by centering yourself in your posture and your breathing. Then, from your heart or from your belly, invite feelings or images of kindness and love to radiate until they fill your whole being. Allow yourself to be cradled by your own awareness as if you were as deserving of loving kindness as any child. Let your awareness embody both benevolent mother energy and benevolent father energy, making available for you in this moment, a recognition and an honoring of your being, and a kindness you perhaps did not receive as a child. Let yourself bask in this energy of loving kindness, breathing it in and breathing it out, as if it were a lifeline, long in disrepair but finally passing along a nourishment you were starving for.

Invite feelings of peacefulness and acceptance to be present in you. Some people find it valuable to say to themselves from time to time such things as: 'May I be free from ignorance. May I be free from greed and hatred. May I not suffer. May I be happy.' But the words are just meant to evoke feelings of loving kindness. They are a wishing oneself well - consciously formed intentions to be free now, in this moment at last, from the problems we so often make for ourselves or compound for ourselves through our fear and forgetfulness. ${ }^{107}$

Following these guidelines, Kabat-Zinn encourages his readers to "bask" in this lovingkindness meditation. Then, he encourages them to direct this energy toward family members, friends, significant others, mentors, strangers, and even people who are difficult to love. ${ }^{108}$

On a personal note, during her master's degree, the author conducted a small research study on anxiety and stress experienced in musicians. For the research study, open-ended

\footnotetext{
${ }^{105}$ Brown, Gifts of Imperfection, 58.

106 Meditation practices are further discussed in Chapter 4.

${ }^{107}$ Kabat-Zinn, Wherever You Go, 164-165.

${ }^{108}$ Kabat-Zinn, Wherever You Go, 166.
} 
interviews were conducted with thirty musicians. Participants were asked questions like: "What elements of a musician's study and career do you think cause stress and anxiety?" "What methods or strategies do you use to cope with this stress and anxiety?" and "As a teacher, student, or performer, how have you observed stress and anxiety in your colleagues and/or students?" One participant's response from this research study embodies perfectionism. When the participant was asked how he coped with stress and anxiety as a musician, he shared his negative coping skills, unlike the other participants who only shared their positive coping skills. To cope with his stress and anxiety, he practiced his instrument incessantly, replaced meals and adequate sleep with coffee, and obsessively beat himself up when he made musical mistakes. Finally, he said, "The only person I've hated the most is myself." When the author shared her findings in a lecture a few months after this interview, she decided to share his self-loathing words with the audience. After speaking these words, the entire audience of musicians, not only the perfectionists, smiled and nodded in agreement. An individual tends to treat him or herself more harshly than he or she would treat another person.

Understanding the negative sides of perfectionism, adopting healthy-striving self-talk instead of perfectionism self-talk, and embracing loving-kindness meditations encourages musicians to find acceptance before and during performances. Additionally, recognizing the destructive nature of perfectionism discourages musicians from identifying their self-worth with their musical mistakes or shortcomings.

Experiencing Flow:

Flow is experienced when musicians soften perfectionism, quiet their inner critics, and cultivate psychological flexibility and acceptance, among many other factors. Flow is a desirable state for musicians because it fully encompasses the present moment and offers moments of deep 
focus and concentration. Mihaly Csikszentmihalyi, Distinguished Professor of Psychology and

Management at Claremont Graduate University, and a leading expert on flow, defines flow as:

A subjective state that people report when they are completely involved in something to the point of forgetting time, fatigue, and everything else but the activity itself. It is what we feel when we read a well-crafted novel or play a good game of squash, or take part in a stimulating conversation. The defining feature of flow is intense experiential involvement in moment-to-moment activity. Attention is fully invested in the task at hand, and the person functions at his or her fullest capacity. ${ }^{109}$

When experiencing flow, individuals generally feel in control, do not worry, and effortlessly merge awareness with action. ${ }^{110}$ Also, they are completely involved and engrossed in their experiences, and evolve from an observer to an active participant. ${ }^{11}$ Finally, they experience an altered sense of time; those who experience flow report time moving quickly due to their total involvement in the experience. ${ }^{112}$ According to Csikszentmihalyi, in order to achieve flow, three specific conditions must be in place: (1) a clear set of goals, (2) a balance between perceived challenge and perceived skill, and (3) a presence of clear and immediate feedback. ${ }^{113}$

First, one can define a clear set of goals prior to a practice session or performance by setting an intention: "May I be focused," "May I be collaborative," "May I be confident," or "May I be present." 114 Another way to define a clear set of goals is to establish a specific goal(s) for a practice session: "I will improve my intonation in this passage," or "I will clean up the fast sixteenth notes in this passage." Setting clear intentions and goals prior to practice sessions and

\footnotetext{
${ }^{109}$ Mihaly Csikszentmihalyi, Flow and the Foundations of Positive Psychology: The collected works of Mihaly Csikszentmihalyi (New York: Springer, 2014), 230, Springer Ebooks.

${ }^{110}$ Csikszentmihalyi, Flow and the Foundations of Positive Psychology, 230.

${ }^{111}$ Csikszentmihalyi, Flow and the Foundations of Positive Psychology, 231.

112 Csikszentmihalyi, Flow and the Foundations of Positive Psychology, 231, 240.

${ }^{113}$ Csikszentmihalyi, Flow and the Foundations of Positive Psychology, 232.

${ }^{114}$ Csikszentmihalyi, Flow and the Foundations of Positive Psychology, 232.
} 
performances encourages musicians to constantly return to that intention or goal when their minds wander, worry, or criticize.

Second, Csikszentmihalyi reflects on the fragile balance between perceived challenge and perceived skill:

When perceived challenges and skills are well matched, as in a close game of tennis or a satisfying musical performance, attention is completely absorbed. This balance, however, is intrinsically fragile. If challenges begin to exceed skills, one typically becomes anxious; if skills begin to exceed challenges, one relaxes and then becomes bored. $^{115}$

When assigning repertoire for a student's jury or upcoming recital, music teachers must be aware of this fragile balance. ${ }^{116}$ Teachers must assign repertoire that is both challenging and accessible, so the student feels motivated to practice, improve, and lead toward feelings of adequacy. Csikszentmihalyi expands on the impact of this fragile balance in motivating and encouraging individuals:

Consider the following example: A person picks up a novel to read. As she begins reading it, she senses that her abilities are not up to the task, that the material is too complex for her to appreciate fully. Feeling unable to take on the challenges of the book because her skills are lacking, she will experience anxiety or boredom, and will probably opt for a less demanding novel or activity. However, if she feels that the complexities of the book are within her capacities and is able to digest the material, her decision either to continue reading the novel or to put it down will be based primarily on her quality of experience while reading the book, namely, the extent to which she finds the book involving and interesting. ${ }^{117}$

In Csikszentmihalyi's book, Finding Flow: The Psychology of Engagement with Everyday Life, he presents a chart that visually depicts this delicate relationship between challenge and skill. For example, if one's skill level is low, and the challenge is high, he or she will not experience flow and may experience anxiety, or if one's skill level is medium, and the

${ }^{115}$ Csikszentmihalyi, Flow and the Foundations of Positive Psychology, 232.

${ }^{116}$ Mihaly Csikszentmihalyi, Finding Flow: The Psychology of Engagement with Everyday Life (New York: Basic Books, 1997), 30.

${ }^{117}$ Csikszentmihalyi, Flow and the Foundations of Positive Psychology, 234. 
challenge is low, he or she will not experience flow and may experience boredom. According to this chart, flow is experienced when skill and challenge levels are both high and balanced. ${ }^{118}$

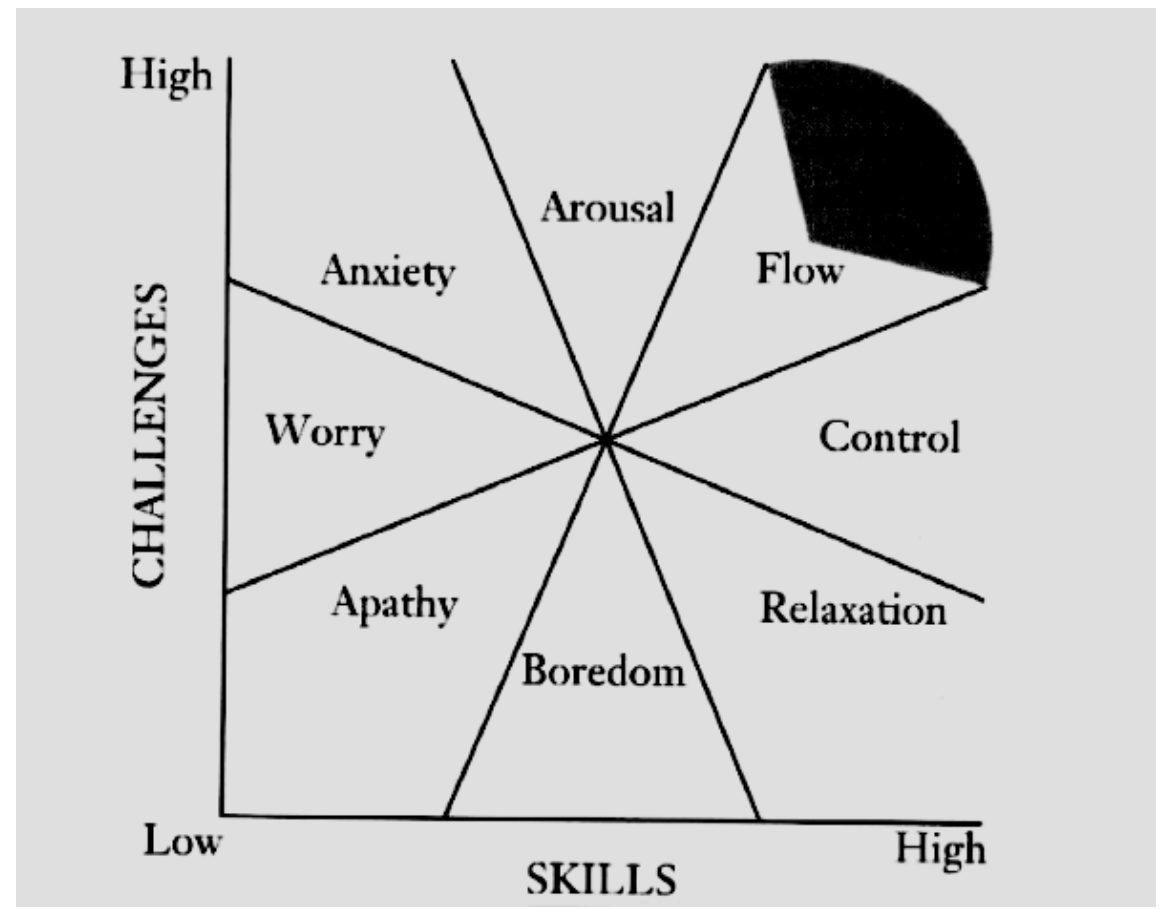

Figure 1. The chart shows that flow occurs when challenge and skill levels are both high. ${ }^{119}$

Third, when people fully understand their environment, their experience, and their desired product for the task at hand, they realize their next course of action without experiencing doubts or uncertainties. ${ }^{120}$ Feelings of doubt can lead to worry and anxiety, which takes people away from the present moment and further away from flow. ${ }^{121}$ Because feelings of doubt and uncertainty take away from the present moment, Csikszentmihalyi also emphasizes that positive feelings of happiness take people away from the present moment, and therefore are not experienced during flow: "When we are in flow, we are not happy, because to experience happiness we must focus on our inner states, and that would take away attention from the task at

${ }^{118}$ Csikszentmihalyi, Finding Flow, 31.

${ }^{119}$ Csikszentmihalyi, Finding Flow, 31.

${ }^{120}$ Csikszentmihalyi, Flow and the Foundations of Positive Psychology, 232.

${ }^{121}$ Csikszentmihalyi, Finding Flow, 30. 
hand." ${ }^{122}$ Sometimes, individuals may reflect on their experiences and feel gratitude and happiness. However, taking the time to think about how happy they feel during an experience takes them away from the present moment: "It is the full involvement of flow, rather than happiness, that makes for excellence in life." ${ }^{, 23}$

So, how often can individuals achieve flow? Csikszentmihalyi conducted a study by asking Americans: "Do you ever become so involved in an activity that you lose track of time?" One in five Americans said yes to this question. These experiences can occur while driving a car, completing projects at work, or spending time with friends. ${ }^{124}$ Therefore, if musicians cultivate mindfulness and develop awareness of their present moments while executing daily tasks like folding laundry, doing the dishes, walking to class, or talking to a friend, they will more likely contact the present moment during high stress performances. Award-winning essayist and poet, Diane Ackerman eloquently discusses how everyday experiences embrace deep play, another description of flow:

For humans, play is a refuge from ordinary life, a sanctuary of the mind, where one is exempt from life's customs, methods, and decrees. Play always has a sacred place - some version of a playground - in which it happens. The hallowed ground is usually outlined, so that it's clearly set off from the rest of reality. This place may be a classroom, a sports stadium, a stage, a courtroom, a coral reef, a workbench in a garage, a church or temple, a field...Play has a time limit, which may be an intense but fleeting moment...Sometimes the time limit is prearranged; at other times it's only recognizable in retrospect...It is its own goal, which it reaches in a satisfying way. ${ }^{125}$

Ackerman's poetic description of deep play matches Csikszentmihalyi discussion of flow. "Play always as a sacred place...clearly set off from the rest of reality:" Flow occurs in specific places, such as the practice room or the stage. "Play has a time limit... sometimes the

${ }^{122}$ Csikszentmihalyi, Finding Flow, 32.

${ }^{123}$ Csikszentmihalyi, Finding Flow, 32.

${ }^{124}$ Csikszentmihalyi, Finding Flow, 33-34.

${ }^{125}$ Diane Ackerman, Deep Play (New York: Random House, Inc, 1999), 6. 
time limit is prearranged; at other times it's only recognizable in retrospect:" When individuals experience flow, their sense of time is altered. For example, a one-hour performance may feel five minutes long. "It is its own goal, which it reaches in a satisfying way:" Csikszentmihalyi discusses that individuals lose awareness of their emotions, thoughts, and worries when they experience flow because they are completely consumed by their experiences and actions. To be free from their emotions, thoughts, and worries is a desirable goal; therefore, flow itself is immensely satisfying. ${ }^{126}$

Flow is a desirable state for musicians due to its complete involvement of the mind, body, and present moment. To experience flow, musicians can set clear intentions, aim to match their skill and challenge levels, and minimize doubt and uncertainty by constantly returning to the present moment. Additionally, musicians can strive to embrace acceptance, soften perfectionism, quiet their inner critics, develop psychological flexibility, and cultivate mindfulness, in order to experience flow.

Musicians in the Present Moment:

Noa Kageyama, creator of The Bulletproof Musician, pursued a master's degree in violin performance at Julliard where he was introduced to Don Greene's course, "Performance Enhancement for Musicians." After completing his master's degree, Kageyama pursued a doctoral degree is psychology at Indiana University, due to Greene's influential course. While studying at Indiana, Kageyama "was determined to learn the secrets of peak performance and find answers to questions like why some people thrive under pressure while others do not." ${ }^{\text {127 }}$

126 Csikszentmihalyi, Finding Flow, 32.

127 "Here's how it all began," The Bulletproof Musician, accessed February 28, 2019, https://bulletproofmusician.com/about. 
After completing his studies, Kageyama founded The Bulletproof Musician, an online platform and course that include skills and resources to help musicians achieve peak performance.

In order to achieve peak performance, Kageyama encourages his students to take a test that assesses their mental strengths and weaknesses. By understanding their weaknesses, musicians better understand why their performances are inconsistent, or why their preparation is not well reflected in performances. ${ }^{128}$ Below is an example figure of the assessment's results. ${ }^{129}$

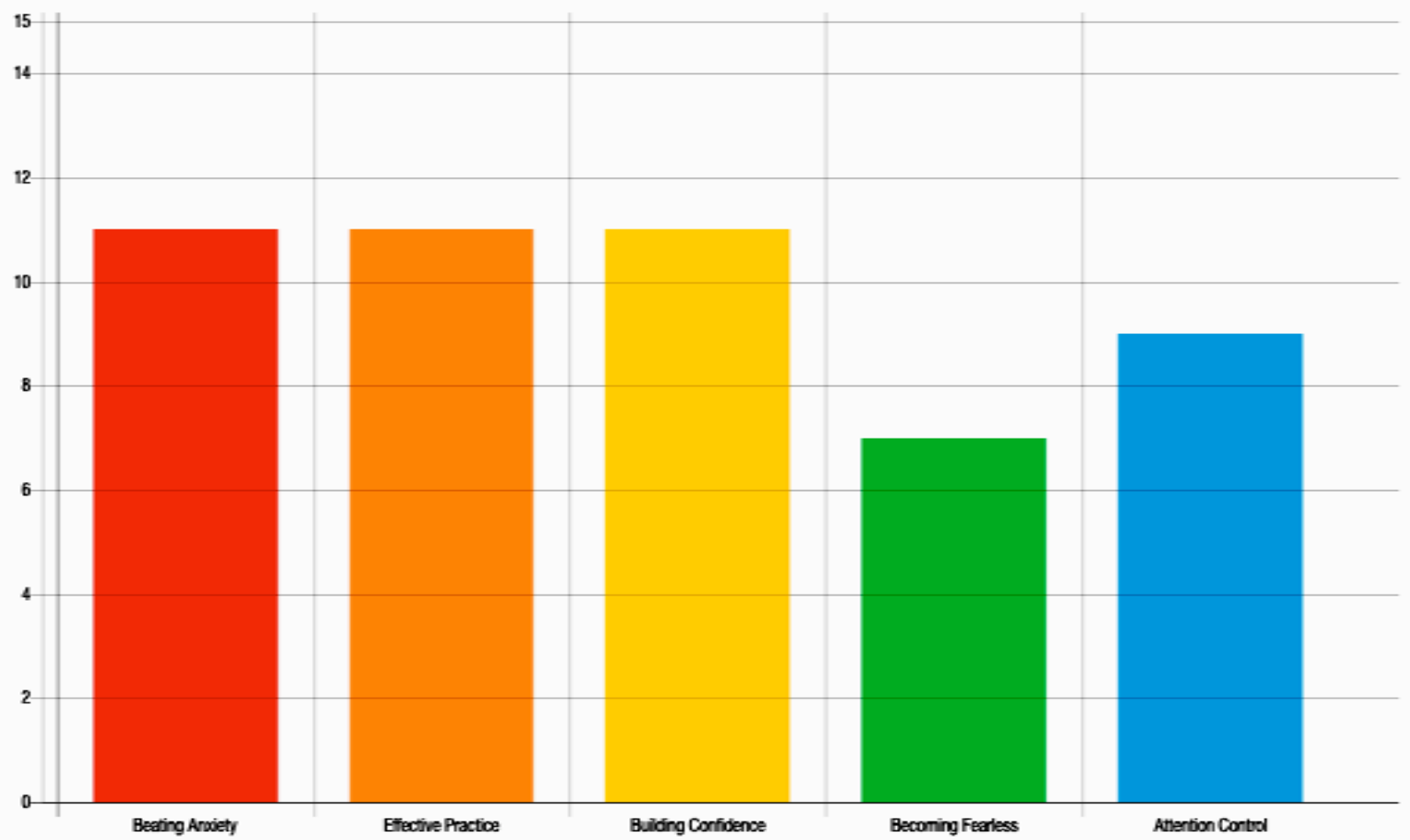

Figure 2. The graph shows differing mental skill scores from the mental skills assessment. ${ }^{\text {su }}$

${ }^{128}$ Noa Kageyama, "Chapter 9: Evaluating Your Mental Strengths and Weaknesses with Dr. Noa Kageyama," interview by Troy Grady, Cracking the Code, Jan. 15, 2016, audio, 2:46, https://troygrady.com/interviews/noa-kageyama/chapter-9-evaluate-your-mental-strengths-andweaknesses.

129 This test can be found on Kageyama's website: "Mental Skills Audit," The Bulletproof Musician, accessed February 28, 2019, https://bulletproofmusician.com/assessment/msa15. 130 "Mental Skills Assessment," The Bulletproof Musician, accessed February 28, 2019, https://bulletproofmusician.com/assessment/msa15-results. 
Kageyama defines the five elements of mental strengths or weaknesses: (1) beating anxiety, (2) effective practice, (3) building confidence, (4) becoming fearless, and (5) attention control/getting in the zone. A high score in beating anxiety shows that one understands how to manage nerves, and feels focused and confident prior to performances. A low score shows that one does not understand how to adjust or diminish stress responses to adrenaline and nerves. A high score in effective practice represents that one knows how to structure practice time, feels prepared for performances, and clearly demonstrates his or her preparation on the stage. A low score represents that one does not know how to structure practice time, and does not know "the difference between practicing for learning and practicing for performing." ${ }^{, 131}$ A high score in building confidence suggests that one understands how to remain productive when faced with challenges and failures. A low score suggests that one does not understand how to remove him or herself from a downward spiral of criticism and failures. A high score in becoming fearless shows that one feels comfortable taking risks on stage and feels confident. A low score shows that one has difficulty taking risks and "letting loose" both on and off the stage. Finally, a high score in attention control/getting in the zone suggests that one knows how to quiet internal thoughts, and how to be in the present moment. A low score suggests that one has difficulty quieting internal thoughts or his or her inner critic while on stage. ${ }^{132}$ After taking this assessment, musicians can consult Kageyama's website or online course to improve their weaknesses, and learn how to capitalize on their strengths.

Another way to achieve peak performance more consistently and to stay in the present moment while performing is to be on "semi-autopilot," as Kageyama defines it. He emphasizes

131 "Mental Skills Assessment," The Bulletproof Musician, accessed February 28, 2019, https://bulletproofmusician.com/assessment/msa15-results.

${ }^{132}$ The Bulletproof Musician, "Mental Skills Assessment." 
that if musicians are on autopilot during a performance, their blank minds tend to dwell on mistakes, worry about upcoming sections in the piece, wonder what the audience is thinking, or fantasize about what to eat after the performance. Kageyama encourages his students to perform on "semi-autopilot" because when on "semi-autopilot," they trust their muscle memory and preparation while staying actively focused on the task at hand. ${ }^{133}$

Also, Kageyama discusses what ideally should occur in a musician's mind during a performance. Kageyama shares principal cellist of The Cleveland Orchestra Mark Kosower's profile: 15 to $20 \%$ monitoring (monitoring and focusing on his technique, the notes, his colleagues, etc.), and 80 to $85 \%$ conceiving the sound he desires. Examples of monitoring are reminding oneself to relax in a difficult section, deliberately changing one's sounding point to be closer to the bridge during a loud section in the piece, or recognizing that the pianist missed the second repeat, so he or she acts quickly and moves forward to the next section. When conceiving the sound one desires, the musician sings the upcoming notes and phrases in his or her mind. When singing or conceiving the sound one desires, the mind has something to focus on instead of emotions, thoughts, or worries.

Finally, Kageyama shares a story from Olympic gymnast, Shawn Johnson, who not only prepares her physical routine, but also prepares her mental routine for competitions. She choreographs what to think about for every physical movement in her routine. By choreographing her thoughts, she does not allow excess emotions, thoughts, and worries to flood through her mind. Although Johnson's "thought choreography” may seem too organized for

${ }^{133}$ Noa Kageyama, "Becoming a Bulletproof Musician," interview by MusicalU, MusicalU, Dec. 19, 2018, audio, 1:12:35, https://www.musical-u.com/learn/becoming-a-bulletproof-musicianwith-noakageyama/?utm_source=mupod_shownotes\&utm_medium $=$ podcast\&utm_campaign $=$ mupodcast 
some people, it demonstrates that everyone, even an Olympic athlete, worries, dwells, and wonders while performing. ${ }^{134}$

To achieve peak performance consistently and be in the present moment while performing, Kageyama encourages musicians to understand their mental strengths and weaknesses, perform on semi-autopilot instead of autopilot, and deliberately decide what to focus on during performances. Adopting these tools encourages musicians to contact the present moment and cope with difficult experiences that arise during high stress performances.

Chapter 4: Mindfulness Exercises

Breathing:

Breathing is a significant aspect of Buddhism and meditation. Buddhism embraces the awareness and observation of one's breath, as opposed to the regulation of one's breath. Also, Buddhism and meditation recognize that although the breath occurs naturally and always exists, the individual decides when to become fully aware of his or her breath. Therefore, the first step for improving one's relationship with breathing is to cultivate awareness of the breath. ${ }^{135}$

Breathing effectively assists musicians in achieving skilled musical performances. Therefore, music teachers and students should take the time in classes or lessons to assess breathing habits. For example, the most effective way to breathe during performances and in everyday life is through diaphragmatic breathing. Babies and young children typically breathe with their entire bellies, or through diaphragmatic breathing. As many people mature, they begin to breathe with the upper part of their lungs, or through chest breathing. ${ }^{136}$ When breathing with

\footnotetext{
${ }^{134}$ Kageyama, "Becoming a Bulletproof Musician," interview.

135 Shonin, Buddhist Foundations of Mindfulness, 58.

${ }^{136}$ Donald Altman, The Mindfulness Toolbox: 50 Practical Tips, Tools and Handouts for Anxiety, Depression, Stress and Pain (Ashland: PESI Publishing and Media 2014), 29, ProQuest Ebook Central.
} 
the upper part of their lungs, individuals become more susceptible to the body's fight-or-flight response. Additionally, the release of serotonin, the body's "feel-good" chemical that is primarily stored in the stomach linings and intestines, is restrained. ${ }^{137}$

Jaume Rosset Llobet and George Odam, authors of The Musician's Body: A Maintenance Manual for Peak Performance, include two exercises that determine if students breathe entirely with their bellies or chests:

100 Count Exercise: First, encourage students to inhale deeply. While exhaling, instruct the students to count out loud quickly. If the students count to a number that is less than 100, they breathe with their chests. If they count to a number that is up to or more than 100 , they breathe with their bellies. ${ }^{138}$

Breathing Adjectives Exercise: Encourage the students to describe how they feel while breathing. If they describe their breathing as difficult, tense, restricted, and labored, they breathe with their chests. If they describe their breathing as relaxed and deep, they breathe with their abdomens. ${ }^{139}$ Marti Olsen Laney, author of The Introvert Advantage: How Quiet People Can Thrive in an Extroverted World, presents another exercise that helps students determine if they breathe with their bellies or chests:

Lay Down Exercise: Encourage the students to lie down on the floor and place a folded towel under their heads and a pillow under their knees. Then, instruct them to place one hand on their chest, and one hand on their abdomen. Encourage the students to take a deep

\footnotetext{
${ }^{137}$ Altman, The Mindfulness Toolbox, 31. The fight-or-flight response is defined later in this chapter.

138 Jaume Rosset Llobet and George Odam. The Musician's Body: A Maintenance Manual for Peak Performance (London: Guildhall School of Music and Drama 2007), 14.

${ }^{139}$ Llobet, The Musician's Body, 14.
} 
breath in and out and observe which hand moves up and down the most. If the chest's hand moves higher than the abdomen's hand, they breathe with their chests. If the abdomen's hand moves higher than the chest's hand, they breathe with their bellies. ${ }^{140}$ If students discover that they breathe with their chests, instead of their bellies, Llobet and Odam present an exercise that helps them rediscover diaphragmatic breathing:

Belly Breathing Exercise: Instruct the students to mentally divide their lungs into three parts. Then, encourage the students to inhale through their noses and focus on the bottom section of their lungs by filling up their stomachs and pushing them outwards (students can place their hands on their stomachs and rib cages to help achieve this). Next, instruct the students to expand their thoraxes (the entire middle section of the body) by raising the ribs to fill the second section of the lungs. Last, tell the students to fill the third part of their lungs by raising their chests. While exhaling, encourage the students to breathe through their mouths, then their lower chests, thoraxes, and ultimately their abdomens. ${ }^{141}$ Finally, breathing helps to cultivate mindfulness by bringing individuals into the present moment when anxiety, thoughts, and worries flood their minds and bodies. Laney offers a "Fivestep Quick Calm Plan" that includes focusing on the breath as the first step, and helps individuals return to the present moment. This exercise is particularly suitable for musicians to implement prior to a performance:

1. Keep breathing. When we experience stress, we hold our breath.

2. Make your eyes calm and alert: Try to alter your facial expression by slightly smiling and calming a furrowed and wrinkled brow. Say to yourself: 'I am alert, and my body is calm.'

\footnotetext{
${ }^{140}$ Marti Olsen Laney, The Introvert Advantage: How Quiet People Can Thrive in an Extrovert World (New York: Workman Publishing 2002), 260.

${ }^{141}$ Llobet, The Musician's Body, 86.
} 
3. Let go of tension: Notice where your body is holding tension: stomach, shoulders, back, jaw? To relax, instead of forcing your body to relax, do the opposite. Tense your entire body, then let go. Shake out your limbs and other body parts.

4. Notice uniqueness: Our minds package certain experiences together and judge these experiences. Try to approach every situation and experience, whether negative or positive as its own unique experience.

5. Call upon your sage: Acknowledge a past experience in which you handled a similar situation and survived. Trust yourself. ${ }^{142}$

When employing effective breathing exercises, breathing can provide various benefits for one's physical, mental, and emotional health. First, breathing centers the mind and calms the body. ${ }^{143}$ Second, breathing deeply improves blood flow and sends oxygen to the brain and muscles, essential for high performance tasks. ${ }^{144}$ Finally, breathing assists with mindfulness, because it serves as a method for returning to the present moment. Music teachers and music students can employ these effective breathing exercises before and during practice sessions, lessons, rehearsals, and performances.

Sleep:

Matthew Walker, a scientist and Professor of Neuroscience and Psychology at the University of California, Berkeley, writes about the powerful benefits of healthy sleep habits. Achieving healthy sleep habits improves one's ability to focus and contact the present moment, among many other mental, emotional, and physical benefits. A musician's ability to recall past information, focus for long periods of time, develop resilience after experiencing disappointment or failure, and cultivate mindfulness, is improved with healthy sleep habits. Musicians can acquire healthy sleep habits by considering the following four factors: (1) biological circadian

\footnotetext{
${ }^{142}$ Laney, Introvert Advantage, 296.

${ }^{143}$ Susan Kaiser Greenland, Mindful Games: Sharing Mindfulness and Meditation with Children, Teens, and Families (Boulder: Shambhala Publications 2016), 13.

${ }^{144}$ Laney, Introvert Advantage, 296.
} 
rhythm, (2) caffeine consumption, (3) alcohol consumption, and (4) hours of sleep gained every night.

“Look across individuals, and you discover that not everyone's circadian rhythm timing is the same." ${ }^{145}$ Understanding one's biological circadian rhythm helps he or she know when to go to sleep, and when his or her optimum time of day for focus and concentration occurs (two elements that are crucial for practice sessions, particularly). Walker organizes individuals into three separate circadian rhythm types: morning types go to bed at 9 p.m. and wake up at 5 a.m., middle types go to bed at 11 p.m./midnight and wake up at 7 a.m./8 a.m., and evening types go to bed at 1 a.m./2 a.m. and wake up at 9 a.m./10 a.m. ${ }^{146}$

First, recognizing their circadian rhythm types will help musicians understand how to organize an ideal practice schedule. For example, morning types may achieve valuable practice time in the morning, as opposed to the evening before bedtime, evening types may achieve valuable practice time in the evening and night since they go to bed in the early morning, and middle types may discover that their most successful practice sessions occur between 8 a.m. and noon, and around 5 p.m. Each type may also discover when their focus and concentration levels diminish throughout the day. For instance, middle types may lose focus in the mid-afternoon, so scheduling a quick workout or a walk in the middle of the day rejuvenates them for their 5 p.m. practice session.

Second, being mindful of one's caffeine consumption greatly affects one's sleeping patterns. The hormone adenosine tells the body to prepare for sleep, but because caffeine is a stimulant, it prevents adenosine from signaling and causes an individual to feel more awake and

${ }^{145}$ Matthew Walker, Why We Sleep: Unlocking the Power of Sleep and Dreams (New York: Scribner, 2017), 20.

${ }^{146}$ Walker, Why We Sleep, 20. 
alert. Caffeine takes thirty minutes after consumption to enter one's system and lasts ten to fourteen hours. ${ }^{147}$ Therefore, if a person drinks coffee at 8 a.m., caffeine will stay in his or her system anytime between 6 p.m. and 10 p.m. When a person drinks a caffeinated energy drink at 3 p.m., caffeine will stay in his or her system between 1 a.m. to 5 a.m. Perhaps replacing a midday caffeine break day with a quick meditation, a workout, or a snack may improve one's ability to fall asleep at night.

Third, grabbing alcoholic drinks after a performance or an audition is a typical social activity for musicians. Their adrenaline is still "kicking," and they want to celebrate with friends over drinks at the bar. However, alcohol consumption inhibits sleeping patterns. According to Walker, alcohol affects people's sleep in two ways. First, consuming alcohol fragments sleep because individuals wake up several times throughout the night (sometimes they don't remember waking up), causing them to feel sluggish the following day. Second, consuming alcohol suppresses rapid eye movement (REM) sleep. REM sleep is crucial for improving one's memory development and stabilizing one's emotional health. ${ }^{148}$

To demonstrate alcohol consumption's impact on sleep, Walker conducted a research study on how alcohol affects the retention of new information or skills. Walker divided his research participants into three groups and taught each group a new computer coding language. The first group drank no alcohol for seven days, the second group became drunk the night of learning this new language, and the third group became inebriated on the third night after learning this new language. After seven days, Walker tested the participants on the same computer coding language taught a week prior. The first group remembered everything they

\footnotetext{
${ }^{147}$ Walker, Why We Sleep, 28.

${ }^{148}$ Walker, Why We Sleep, 272.
} 
learned seven days prior, the second group forgot $50 \%$ of what they learned, and the third group forgot $40 \%$ of what they learned. ${ }^{149}$

A musician's memory is crucial for his or her musical improvement and development. If musicians drink to excess just one night of every week, their memories of new techniques, skills, and pieces are greatly affected. In fact, Walker discusses that muscle memory is a misleading term: "Muscles themselves have no such memory: a muscle that is not connected to a brain cannot perform any skilled actions, nor does a muscle store skilled routines. Muscle memory is, in fact, brain memory...the routine itself - the memory program - resides firmly and exclusively within the brain."150

Last, sleeping for a full eight hours every night is crucial for memory, focus and concentration levels, the prevention of playing-related injuries, and the stabilization of emotional health. In the last two hours of an eight-hour night of sleep, stage two non-rapid eye movement (NREM) sleep occurs, which cements one's memory. ${ }^{151}$ Many people sleep less than eight hours a night throughout the week and use the weekends to catch up on sleep. In response to this, Walker writes: "If you don't sleep the very first night after learning, you lose the chance to consolidate those memories, even if you get lots of 'catch-up' sleep thereafter.",152

Also, focus and concentration levels are negatively affected by sleep deprivation. ${ }^{153}$ Walker writes about a research study conducted by David Dinges, a sleep researcher and Professor of Psychology in Psychiatry at the University of Pennsylvania's School of Medicine. Dinges created a simple concentration exercise for four groups of participants: press a button in

\footnotetext{
${ }^{149}$ Walker, Why We Sleep, 273.

${ }^{150}$ Walker, Why We Sleep, 123.

${ }^{151}$ Walker, Why We Sleep, 127.

${ }^{152}$ Walker, Why We Sleep, 157.

${ }^{153}$ Walker, Why We Sleep, 134.
} 
response to a light that appears on a computer screen. The first group did not sleep for seventytwo hours straight, and by the fourth day, their missed responses increased by over $400 \%$. The second group slept only four hours a night, and by the sixth day, their missed responses increased by $400 \%$. The third group slept for six hours a night, and by the tenth day, their missed responses increased by $400 \%$. The fourth group slept for eight hours every night, and had no notable lapses in focus and concentration. ${ }^{154}$ This study shows that people cannot cut "corners" when it comes to sleep. Eight hours a night is crucial and beneficial for one's focus and concentration levels.

Additionally, because musicians use their bodies every day, they are susceptible to playing-related injuries. Fortunately, adequate sleep can lesson the chances of a playing-related injury. In fact, acquiring adequate sleep after a performance or long practice session is essential for injury prevention because sleep reduces inflammation and repairs muscles. ${ }^{155}$ Walker outlines how many hours of sleep per night affects one's chance of getting a playing-related injury: six hours of sleep per night produces a 70\% chance of injury, seven hours of sleep per night produces a $60 \%$ chance of injury, eight hours of sleep per night produces a $35 \%$ chance of injury, and nine hours of sleep per night produces a $15 \%$ chance of injury. ${ }^{156}$

Finally, sleep stabilizes one's emotional health, which is greatly linked to cultivating mindfulness. Mindfulness cannot be cultivated when one reacts quickly and negatively to emotions, thoughts, and worries. Walker writes:

With a full night of plentiful sleep, we have a balanced mix between our emotional gas pedal (amygdala) and brake (prefrontal cortex) - (rational part of brain). Without sleep, however, a strong coupling between these two brain regions is lost... Without the rational control given to us each night by sleep, we're not on a neurological - and hence emotional - even keel. ${ }^{157}$

\footnotetext{
${ }^{154}$ Walker, Why We Sleep, 135.

${ }^{155}$ Walker, Why We Sleep, 129.

${ }^{156}$ Walker, Why We Sleep, 129.

${ }^{157}$ Walker, Why We Sleep, 147.
} 
Sleep enriches one's cultivation of mindfulness because it regulates focus and concentration levels, and stabilizes one's emotional health. If musicians adopt healthy sleep habits while practicing and rehearsing for upcoming juries, recitals, and auditions, they will likely improve their memory retention, prevent playing-related injuries, and manage their reactions to harsh, negative emotions. ${ }^{158}$

Rest and Recovery:

When musicians do not adequately rest and recover after high stress or high adrenaline performances, they more likely experience physical, mental, and emotional exhaustion, otherwise known as burnout. To prevent burnout, musicians must incorporate rest and recovery at appropriate times between practice sessions, rehearsals, and performances. ${ }^{159}$ Being mindful of their concentration and focus levels while practicing helps them find appropriate moments for rest.

When we are alert, our heart rate, hormonal levels, muscle tension and brain-wave activity all increase. After an hour or so, these measures start to decline. Somewhere between 90 and 120 minutes, the body begins to crave a period of rest and recovery. This segment includes: yawning, stretching, hunger, increased tension, low concentration, fantasizing, and more mistakes. ${ }^{160}$

Burnout occurs when individuals ignore rest and frequently rely on their fight-or-flight response. ${ }^{161}$ When their bodies enter the fight-or-flight response, stress hormones that are typically associated with emergencies are released. When individuals constantly use these stress

\footnotetext{
${ }^{158}$ To further learn how to adopt healthy sleep habits and patterns, consult Mayo Clinic's website: "Mayo Clinic," Mayo Clinic, accessed April 19, 2019, https:/www.mayoclinic.org. ${ }^{159}$ Loehr, The Power of Full Engagement, 29.

${ }^{160}$ Loehr, The Power of Full Engagement, 31.

${ }^{161}$ Fight-or-flight response: A survival mechanism for mammals and human beings to react quickly to life-threatening experiences. The response combines hormonal changes and physiological responses to help a mammal or human being to fight the threat, or flee from the threat.
} 
hormones, their bodies and minds become physically, mentally, and emotionally exhausted, and they experience burnout. Because stress hormones, such as adrenaline, noradrenaline, and cortisol offer a heightened state of arousal, they can be addictive. ${ }^{162}$ Therefore, high amounts of work and stress paired with low amounts of recovery and rest can often lead to the obsessivecompulsive disorder, workaholism. ${ }^{163}$

How can musicians implement adequate rest after a high stress performance? Jim Loehr, author of The Power of Full Engagement: Managing Energy, Not Time, Is the Key to High Performance and Personal Renewal, encourages his readers to participate in consuming and engaging activities for "the pure joy of it." ${ }^{\text {164 }}$ Examples of engaging activities are: exercising, attending a yoga class, taking a hot bath, gardening, reading an absorbing book, spending time with a loved one, visiting a museum, attending a concert, or cooking. Loehr strongly encourages his readers to not rely on watching television as a tool for rest because it does not completely absorb the mind. In fact, Csikszentmihalyi discovered that binge-watching television is associated with anxiety and low-level depression. ${ }^{165}$

Finally, Loehr emphasizes the importance of rest not only after a high stress event, but also after an emotionally draining event. Recovering emotionally from a high stress event is just as important as recovering physically and mentally. ${ }^{166}$ For example, musicians may prepare for an audition for several months. After finally taking the audition, they discover that they do not pass to the second round of auditions; they not only feel mentally and physically drained, but they also feel emotionally drained due to experiencing emotions like disappointment, regret,

\footnotetext{
${ }^{162}$ Loehr, The Power of Full Engagement, 39.

${ }^{163}$ Loehr, The Power of Full Engagement, 40.

${ }^{164}$ Loehr, The Power of Full Engagement, 76.

${ }^{165}$ Loehr, The Power of Full Engagement, 77.

${ }^{166}$ Loehr, The Power of Full Engagement, 84.
} 
anger, and sadness. In The Power of Full Engagement, Loehr encourages his readers to engage in an enjoyable activity that offers emotional renewal after a high stress event: "Any activity that is enjoyable, fulfilling and affirming tends to prompt positive emotions."

Laney, author of The Introvert Advantage, emphasizes how understanding one's introverted or extroverted traits also helps one understand and identify when to incorporate rest and recovery practices into his or her daily routine. For example, introverts gain energy by being alone and extroverts gain energy by being around other people. To identify whether they are introverts or extroverts, Laney provides a self-assessment for her readers to complete. After discovering whether they are introverts or extroverts, Laney encourages her readers to observe their energy levels throughout an entire day in order to understand when and how long they need to rest. For example, if an introvert has a big performance on a Saturday night, Laney advises the introvert to not go out with friends on Friday night in order to conserve energy for Saturday's performance. Finally, Laney discusses the importance of frequently scanning one's body and mindfully noting one's energy levels: "If you are an introvert and you notice your head is buzzing, and your body is exhausted, you need to take a break. If you had a quiet weekend indoors, you feel energized."

Implementing rest and recovery during and after practice sessions, rehearsals, and performances prevents musicians from overusing their stress hormones and experiencing burnout. Effective rest and recovery is achieved through engaging activities that fully consume the mind, such as reading, exercising, or talking to a friend. Every individual requires different amounts and different forms of rest and recovery due in part to their introverted and extroverted tendencies.

\footnotetext{
${ }^{167}$ Loehr, The Power of Full Engagement, 76.

${ }^{168}$ Laney, The Introvert Advantage, 58.
} 


\section{Exercise:}

For some individuals, cultivating mindfulness through movement is helpful. In fact, exercising itself is a form of mindfulness. For example, when individuals run, their heart rates rise, their bodies' sweat, and their stomachs cramp, yet they continue to run by accepting these sensations and staying in the present moment. Additionally, exercise helps people develop the ability to switch quickly between moments of stress and periods of recovery. Josh Waitzkin, world-renowned chess player, martial arts competitor, and author of The Art of Learning, writes: "In virtually every discipline, one of the most telling features of a dominant performer is the routine use of recovery periods. Players who are able to relax in brief moments of inactivity are almost always the ones who end up coming through when the game is on the line."169

To implement stress and recovery training, Waitzkin encourages readers to incorporate interval training into their exercise regimens in order to develop the ability to recover quickly from increased heart rates, rushes of adrenaline, and moments of stress. ${ }^{170}$ Stress and recovery training can be applied to several different exercise regimens, such as jogging, sprinting, and biking, for example. When employing stress and recovery training, Waitzkin encourages his readers to gradually increase "sprint" durations, and decrease recovery durations. This not only helps one learn how to recover more quickly during high stress experiences, but also improves one's resilience when faced with these experiences. ${ }^{171}$ Finally, Waitzkin discusses the beneficial results of stress and recovery training for individuals' everyday lives: "As we get better and better at releasing tension and coming back with a full tank of gas in our everyday activities, both

\footnotetext{
169 Josh Waitzkin, The Art of Learning (New York: Simon and Schuster, 2007), 179.

${ }^{170}$ Waitzkin, The Art of Learning, 181.

${ }^{171}$ Waitzkin, The Art of Learning, 181.
} 
physical and mental, we will gain confidence in our abilities to move back and forth between concentration, adrenaline flow, physical exertion (any kind of stress), and relaxation." ${ }^{\prime 12}$

When employing stress and recovery interval training, musicians learn to accept unpleasant sensations, such as physical pain, and learn to replenish their minds and bodies more quickly after high stress experiences. Additionally, due to its emphasis on acceptance and resilience, stress and recovery training may also help musicians cultivate mindfulness. ${ }^{173}$ Yoga:

Five thousand years ago, the Indus-Sarasvati civilization, located in modern-day Pakistan and Northwest India, established the practice of yoga. Over the past 5,000 years, yoga evolved through various civilizations and belief systems. Between the second century BCE and the fourth century CE, Pantanjali, "the father of yoga," wrote the first text on yoga, Yoga-Sutras. Many centuries after Pantanjali, yoga incorporated body-focused practices, "embraced the physical body as a means to enlightenment," and evolved into Hatha yoga. ${ }^{174}$ In the 1800 s and 1900s, Hatha yoga produced influential yogis in India, such as T. Krishnamacharya, B.K.S. Iyengar, T.K.V. Desikachar and Pattabhi Jois. During the 1900s, Hatha yoga migrated to the West, and in the 1940s, Indra Devi, a student of T. Krishnamacharya, opened up a yoga studio in Hollywood. Her yoga studio greatly impacted yoga's popularity in the United States. ${ }^{175}$ Today, yoga consists of several practices and styles that embrace a different focus or pace, such as Vinyasa yoga and

\footnotetext{
172 Waitzkin, The Art of Learning, 184.

173 To further learn how to adopt effective and mindful exercise regimens, and learn the benefits of exercise, consult Mayo Clinic's website: "Mayo Clinic," Mayo Clinic, accessed April 19, 2019, https://www.mayoclinic.org. 174 "History of Yoga," Yoga Basics, accessed February 22, 2019, http://www.yogabasics.com/learn/history-of-yoga.

${ }^{175}$ Yoga Basics, "History of Yoga."
} 
Restorative yoga. Vinyasa yoga effortlessly flows from one pose to another, while Restorative yoga embraces relaxation and healing, and utilizes props, like blocks, blankets, and cushions. ${ }^{176}$

Because Hatha yoga serves as one of the most popular yoga practices in the West, this section focuses on Hatha yoga's philosophies, created by Swami Swatmarama in the fifteenth and sixteenth centuries. ${ }^{177}$ The main focus of Hatha yoga is mastering self-control and selfdiscipline in the body, and bringing awareness to physical sensations, thoughts, and feelings that occur while executing different movements. ${ }^{178}$ Hatha yoga utilizes several practices and techniques for gaining self-control and self-discipline, and restoring the body and mind. According to Swatmarama, these practices and techniques lead to deep states of meditation and spiritual enlightenment. ${ }^{179}$ The following five practices are: (1) asana: yoga postures, (2) pranayama: breathing exercises, (3), shatkarma: cleansing of toxins to allow the energy to move through the body, (4) mudra: sealing energy in the body, and (5) bandha: locking the energy in the body. ${ }^{180}$

Yoga is deeply connected with mindfulness due its emphasis on meditation, the breath, stress and tension release, and setting intentions prior to and during practices. In fact, Kabat-Zinn compares yoga to mindfulness: "Yoga folds movement and stillness into one another. It is a wonderfully nourishing practice. As in other forms of mindfulness practice, you are not trying to

176 “Yoga Styles: One Word Definitions,” Yoga Basics, accessed February 22, 2019, http://www.yogabasics.com/connect/yoga-blog/yoga-styles-one-word-definitions.

${ }^{177}$ If you want to learn about other yoga practices, refer to: "Philosophy of Yoga," Yoga Basics, accessed February 22, 2019, http://www.yogabasics.com/learn/philosophy-of-yoga.

${ }^{178}$ Kabat-Zinn, Wherever You Go, 157.

179 "Hatha Yoga Pradipika,” Yoga Basics, accessed February 22, 2019, http://www.yogabasics.com/learn/hatha-yoga-pradipika.

180 "Hatha Yoga Pradipika," Yoga Basics, accessed February 22, 2019, http://www.yogabasics.com/learn/hatha-yoga-pradipika. 
get anywhere. But you are purposefully moving right up to the very limits of your body in this moment."181

Similar to exercise, yoga serves as a tool for practicing mindfulness through movement, and serves as an additional method in cultivating a musician's mindfulness skills for practice sessions, rehearsals, and performances. To practice yoga, consult the website, Yoga Basics, or attend a yoga class at a yoga studio or gym. ${ }^{182}$

Meditation:

Like breathing, exercise, and yoga, meditation serves as an additional method for cultivating mindfulness. Although many people associate meditation strictly with relaxation, it does not always produce feelings of calm, peace, and comfort. Kabat-Zinn emphasizes how meditation requires effort, energy, and discipline, and discusses the value of meditation: "It is an intrinsically satisfying work because it puts us in touch with many aspects of our lives that are habitually overlooked and lost to us."

In Calming Your Anxious Mind, Brantley further elaborates on common misconceptions surrounding meditation and mindfulness:

Not positive thinking: Meditation is the act of paying attention to thinking, whether positive, negative, or neutral.

Not a relaxation technique: Meditation demands awareness of one's habits and reactions.

Not going into a trance: Meditation does not serve as an escape from reality, but encourages the individual to stay present in the moment. ${ }^{184}$

${ }^{181}$ Kabat-Zinn, Wherever You Go, 157.

${ }^{182}$ Consult YogaBasics online for information on yoga postures: "Yoga Postures," Yoga Basics, accessed February 22, 2019, http://www.yogabasics.com/practice/yoga-postures.

${ }^{183}$ Kabat-Zinn, Wherever You Go, 8.

184 Brantley, Calming Your Anxious Mind, 67. 
Not "blanking your mind": When practicing mindfulness and meditation, the individual is deeply conscious and connected with the present moment, not numb to it: “...it is a willingness to go nose to nose with pain, confusion, and loss, if that is what is dominating the present moment..."185

Not just for priests, monks, and nuns: "Meditation is a way of remembering and reconnecting with the natural quality of awareness and presence all humans have."186

Not selfish: Because mindfulness and meditation increases one's awareness, he or she will become more helpful, present, and compassionate toward oneself and others. ${ }^{187}$ In Wherever You Go, There You Are, Kabat-Zinn includes various meditations and techniques that enrich one's meditation practices. First, he encourages his readers to think of themselves as witnesses to their experiences and emotions by asking the following questions: "What is happening? What is this? What do I see? What do I hear? What do I feel?" Before performances, many musicians' minds worry: "Who is in the audience? Did I tune perfectly? What if my dress unzips?" Instead of worrying about circumstances and people they cannot change, Kabat-Zinn encourages his readers to witness what they feel, see, and hear. When people become witnesses to their experiences, they contact the present moment more readily. ${ }^{188}$

Kabat-Zinn also includes the "die on purpose" meditation, also known as the stopping meditation. In this meditation, he encourages his readers to stop and witness the moment as it is. When individuals become witnesses to their experiences, their lives seem simpler; they stop planning, worrying, wondering, and rushing, and witness the moment for what it is. Kabat-Zinn

\footnotetext{
${ }^{185}$ Kabat-Zinn, Wherever You Go, 111. 186 Brantley, Calming Your Anxious Mind, 67.

${ }^{187}$ Brantley, Calming Your Anxious Mind, 67.

${ }^{188}$ Kabat-Zinn, Wherever You Go, 11.
} 
relates this stopping meditation to dying for a moment because when individuals take the time to simply stop, their worries and obligations briefly dissipate: ${ }^{189}$

By taking a few moments to 'die on purpose' to the rush of time while you are still living, you free yourself to have time for the present. By 'dying' now in this way, you actually become more alive now. This is what stopping can do. There is nothing passive about it. And when you decide to go, it's a different kind of going because you stopped. The stopping actually makes the going more vivid, richer, more textured. It helps keep all things we worry about and feel inadequate about in perspective. It gives us guidance. ${ }^{190}$

Because performances are often scheduled on arbitrary days, accepting one's preparation and skill level prior to a performance is extremely difficult. This "die on purpose" meditation can serve as an effective way to accept one's experience, and let go of worries, inadequacies, and strong emotions prior to a performance.

Musicians can include meditation in their daily life through various avenues. First, KabatZinn's Wherever You Go, There You Are offers different types of meditations like breathing, sitting, walking, and standing meditations. Second, cell phone apps like Calm and Headspace offer guided meditations that are easy to access. Third, many universities offer weekly guided meditations at the counseling facilities. Last, musicians can meditate on their own by sitting still for ten minutes a day, focusing on their breath, and witnessing their emotions.

Meditation encourages individuals to witness their experiences as they are, whether positive, negative, or neutral. Because meditation focuses on the act of witnessing one's experience, it can help musicians cultivate mindfulness by encouraging them to witness their experiences for what they are, accept their experiences, and return to the present moment.

${ }^{189}$ Kabat-Zinn, Wherever You Go, 11. 


\section{Chapter 5: "Mindfulness for Musicians" Course}

The "Mindfulness for Musicians" course, designed by the author, focuses on teaching music students how to cultivate mindfulness through practical skills and methods in an academic environment. The "Mindfulness for Musicians" course is intended for undergraduate and/or graduate music students. Although the course is designed for a classroom setting, the course's topics, readings, and assignments can be reinterpreted for private lesson teaching, as well. This course is designed to meet once a week for fifty minutes for one academic semester (fifteen weeks). This chapter includes a syllabus, schedule, assigned readings, and an in-depth description for each assignment.

Syllabus:

Purpose:

1. To understand mindfulness' history, definition, origins, and influence on Western medicine. 2. To gain knowledge of how the psychology and sport psychology fields utilize mindfulness, and reinterpret this knowledge for musicians.

3. To learn skills and methods that assist in cultivating mindfulness.

4. To reflect on how implementing these skills and methods impacts one's journey in cultivating mindfulness.

Format:

This class will meet once a week for fifty minutes. Two classes will meet at the university's recreation center, and one class will meet at the university's counseling center.

Course Requirements:

1. Notebook for notes and journal entries

2. Three-ring binder for hand-outs

3. A yoga mat (not required, but encouraged)

Course Resources:

We will read selections from various publications. These selections are posted online.

\section{Grading:}

There are no exams for this course. Grades are determined by the timely submission of required assignments, participation in class discussions, and attendance. 
Assignment Description:

An in-depth description of each course assignment is included after the course schedule in this document.

Course Schedule and Assigned Readings:

Weeks 1-3: Learning about Mindfulness

Week 1. History of Mindfulness and What Mindfulness is NOT

Reading Selections:

1. Jon Kabat-Zinn, Wherever You Go, There You Are: Mindfulness Meditation in Everyday Life

2. Laury Rappaport, "Mindfulness, Psychotherapy, and the Arts Therapies," Mindfulness and the Arts Therapies: Theory and Practice

3. Edo Shonin, William Van Gordon, and Nirbay N. Singh, Buddhist Foundations of Mindfulness

4. Sam J. Zizzi and Mark B. Anderson, Being Mindful in Sport and Exercise Psychology:

Pathways for Practitioners and Students

Assignment \#1:

1. Reflection: Write a two-page double-spaced reflection on Week 1's readings and the discussion from the first class period, considering the questions that are outlined in the Assignment Description hand-out.

Week 2. Mindfulness in Western Medicine: Mindfulness-based therapies

Reading Selections:

1. Karolyn A. Gazzella, "Jon Kabat-Zinn, PhD Bringing Mindfulness to Medicine," in Alternative Therapies in Health and Medicine

2. Frank Gardner and Zella E. Moore, "Mindfulness-Acceptance-Commitment (MAC) for Performance Development (PD), " Clinical Sports Psychology

Assignment \#2:

1. Reflection: Write a two-page double-spaced reflection on Week 2's readings and the discussion from the class period, considering the questions that are outlined in the Assignment Description hand-out.

$\underline{\text { Week 3. Mindfulness in Athletes and Musicians }}$

Guest Lecturer: Edward Etzel, EdD, Licensed Psychologist, Certified Mental Performance

Coach, Sports Shooter and Olympic Champion

Reading Selections:

1. Ellie H. Falter, "Mindfulness: An Underused Tool for Deepening Music Understanding," General Music Today

2. Don Greene, Performance Success: Performing Your Best Under Pressure 
3. Mike Gross, Zella E. Moore, Frank L. Gardner, Andrew T. Wolanin, Rachel Pess and Donald R. Marks, "An empirical examination comparing Mindfulness-Acceptance-Commitment approach and Psychological Skills Training for the mental health and sport performance of female student athletes," International Journal of Sport and Exercise Psychology

4. Noa Kageyama, The Bulletproof Musician

5. Oscar Lecuona de la Cruz and Raquel Rodriguez-Carajal, "Mindfulness and Music: A Promising Subject of an Un-Mapped Field," International Journal of Behavioral Research and Psychology

Assignment \#3:

Reflection: Write a two-page double-spaced reflection on Week 3's readings and the guest lecturer's discussion from the class period, considering the questions that are outlined in the Assignment Description hand-out.

Weeks 4-5: Mindfulness and Emotions

Week 4. The Role of Emotions: Physiological responses to intense emotions like fear, panic, worry, and anxiety

Guest Lecturer: Ashley Kasardo, PsyD, Clinical Psychologist

Reading Selections:

1. Jeffrey Brantley, Calming Your Anxious Mind: How Mindfulness and Compassion Can Free You from Anxiety, Fear, and Panic, $2^{\text {nd }}$ edition

Assignment \#4:

Reflection: Write a two-page double-spaced reflection on Week 5's readings and the guest lecturer's discussion from the class period, considering the questions that are outlined in the Assignment Description hand-out.

Week 5. How Cultivating Mindfulness Helps to Acknowledge and Accept our Emotions

Reading Selections:

1. Donald Altman, The Mindfulness Toolbox: 50 Practical Tips, Tools and Handouts for Anxiety, Depression, Stress and Pain

Assignment \#5:

Application and Journal Reflection: Choose one of the tools presented in Altman's The Mindfulness Toolbox, and employ this tool every day. For six days, write a one-page journal entry on your experience incorporating this tool in your everyday routine. Consider the questions that are outlined in the Assignment Description handout.

Weeks 6-9: Being in the Present Moment

Week 6. Developing Psychological Flexibility 
Reading Selections:

1. Telmo Serrano and Helena Amaral Espirito-Santo, "Music, ballet, mindfulness, and psychological inflexibility," Psychology of Music

2. Susan M. Orsillo, Acceptance and Mindfulness-based Approaches: Conceptualization and Treatment

Assignment \#6:

Application and Journal Reflection: Challenge yourself to develop awareness of your thoughts and to cultivate psychological flexibility this week. For six days, write a one-page journal entry on your experience incorporating psychological flexibility into your everyday routine. Consider the questions that are outlined in the Assignment Description handout.

\section{Week 7. Calming Your Inner Critic}

Reading Selections:

1. Mark Coleman, Make Peace With Your Mind: How Mindfulness and Compassion Can Free Your Inner Critic

Assignment \#7:

Inner Critic Tally Challenge: Download a free app that tracks tallies (Tally Counter or The Count), or use a small notebook that you can easily access during classes, practice sessions, rehearsal breaks, and study sessions. For three consecutive days (8 a.m. to 8 p.m.), mark a tally each time you notice a harsh, unproductive critique about yourself occur in your mind. Write a two-page double-spaced reflection on this challenge. Consider the questions that are outlined in the Assignment Description handout.

Week 8. Finding Acceptance and Softening Perfectionism

Guest Lecturer: Leigh Skvarla, PhD, NCC, Peak Performance Consultant and Clinical Counselor

Reading Selections:

1. Brene Brown, The Gifts of Imperfection: Let Go of Who You Think You're Supposed to Be and Embrace Who You Are

2. Don Greene, Performance Success: Performing Your Best under Pressure

3. Judith Kogan, Nothing But The Best: The Struggle for Perfection at the Julliard School

Assignment \#8:

Reflection: Write a three-page double-spaced reflection on Week 8's readings and the guest lecturer's discussion from the class period, considering the questions that are outlined in the Assignment Description hand-out.

Week 9. Achieving Flow

Reading Selections:

1. Diane Ackerman, Deep Play 
2. Mihaly Csikszentmihalyi, Flow and the Foundations of Positive Psychology: The collected works of Mihaly Csikszentmihalyi

3. Mihaly Csikszentmihalyi, Finding Flow: The Psychology of Engagement with Everyday Life

Assignment \#9:

Application and Journal Reflection: Be mindful of what experience(s), no matter how small or how brief, bring flow to your day-to-day routine. For six days, briefly write about the experience(s) that brought you flow, and what factors contributed to experiencing flow. See the Assignment Description hand-out for examples of flow factors and experiences.

\section{Weeks 10-14: Mindfulness Exercises}

Week 10. The Importance of Deep Breathing: Breathing exercises

Reading Selections:

1. Donald Altman, The Mindfulness Toolbox: 50 Practical Tips, Tools and Handouts for Anxiety, Depression, Stress and Pain

2. Susan Kaiser Greenland, Mindful Games: Sharing Mindfulness and Meditation with Children, Teens, and Families

3. Jaume Rosset Llobet and George Odam, The Musician's Body: A Maintenance Manual for

Peak Performance

Assignment \#10:

Application and Journal Reflection: Incorporate one of the breathing exercises that we employed in class, or one of the breathing exercises that you read about from the reading selections, prior to an experience that provokes stress, anxiety, nervousness, etc. for you (For example: a performance, a lesson, a rehearsal, a practice session, a date, a class, etc.). For six days, write a one-page journal entry on your experience utilizing this breathing exercise, considering the questions that are outlined in the Assignment Description hand-out.

Week 11. The Importance of Sleep and Rest

Reading Selections:

1. Marti Olsen Laney, The Introvert Advantage: How Quiet People Can Thrive in an Extroverted World

2. Jim Loehr and Tony Schwartz, The Power of Full Engagement: Managing Energy, Not Time, Is the Key to High Performance and Personal Renewal

3. Matthew Walker, Why We Sleep: Unlocking the Power of Sleep and Dreams

Assignment \#11 and \#12:

Reflection: Write a two-page double-spaced reflection on Week 11's readings and the discussion from the class period, considering the questions that are outlined in the Assignment Description hand-out.

Application and Journal Reflection: For six days, log your sleep patterns in your journal. Every night, write down how many hours of sleep you achieved the night before, if you took any naps, 
how much caffeine you consumed, and whether or not you dedicated time during the day to rest (rest can be defined as dinner with a good friend, a walk, a meditation, listening to music, closing your eyes for five minutes, etc.). Then, reflect on your productivity, activity, mood, and concentration levels in the morning, afternoon, and evening of each day.

Week 12. Mindfulness and Physical Exercise: Stress and Recovery Interval training

*Class meets on the track at the university's recreation center

Reading Selections:

1. Josh Waitzkin, The Art of Learning

Assignment \#13:

Reflection: Write a two-page double-spaced reflection on Week 12's reading and your experience with stress and recovery interval training at the recreation center, considering the questions that are outlined in the Assignment Description hand-out.

Week 13. The History and Practice of Yoga: Yoga poses

*Class meets at the university's recreation center

Reading Selections:

1. Timothy Burgin, Yoga Basics Website

Assignment \#14:

Reflection: Write a two-page double-spaced reflection on Week 13's reading and your experience in yoga class, considering the questions that are outlined in the Assignment Description hand-out.

Week 14. The Practice of Meditation

*Class meets at the university's counseling center

Reading Selections:

1. Jon Kabat-Zinn, Wherever You Go, There You Are: Mindfulness Meditation in Everyday Life

Assignment \#15:

Reflection: Write a two-page double-spaced reflection on Week 14's reading and your experience meditating, considering the questions that are outlined in the Assignment Description hand-out.

Week 15: Mindfulness as a Lifestyle

Week 15. The Interconnectedness of Mindfulness

Reading Selections:

1. Josh Waitzkin, The Art of Learning

2. Jeffrey Brantley, Calming Your Anxious Mind: How Mindfulness and Compassion Can Free You from Anxiety, Fear, and Panic, $2^{\text {nd }}$ edition 
Assignment \#16:

Final Reflection Paper: Write a five-page double-spaced reflection on your experience taking this "Mindfulness For Musicians" course, considering the questions outlined in the Assignment Description handout.

Assignment Description:

Week 1:

Reflection: Write a two-page double-spaced reflection on the assigned readings for Week 1, and the first class period's discussion. When citing material from the readings, include footnotes and proper citations in Chicago Manual of Style. Consider the following questions when writing your reflection:

1. Prior to meeting for the first class, how did you define mindfulness?

2. Now that you understand the description and definition of mindfulness, do you believe that musicians are already mindful?

3. Reflecting on specific performance and practice settings, what types of thoughts, worries, or negative self-talk arise for you? How might cultivating mindfulness alleviate or calm these thoughts, worries, or inner dialogues?

Week 2:

Reflection: Write a two-page double-spaced reflection on the assigned readings for Week 2, and the class period's discussion. When citing material from the readings, include footnotes and proper citations in Chicago Manual of Style. Consider the following questions when writing your reflection:

1. How might musicians benefit from utilizing the Mindfulness-Acceptance-Commitment (MAC) model?

2. How might musicians benefit from undergoing Mindfulness-based Stress Reduction (MBSR) therapy?

3. How might musicians adopt the skills and ideas demonstrated in MAC or MBSR if they do not have access to therapeutic treatment?

Week 3:

Reflection: Write a two-page double-spaced reflection on the assigned readings for Week 3, and the guest lecturer's discussion. When citing material from the readings, include footnotes and proper citations in Chicago Manual of Style. Consider the following questions when writing your reflection:

1. What parallels or similarities do athletes and musicians experience in their training?

2. How might mindfulness assist athletes and musicians to achieve peak performance?

Week 4:

Reflection: Write a two-page double-spaced reflection on the assigned readings for Week 4, and the guest lecturer's discussion. When citing material from the readings, include footnotes and proper citations in Chicago Manual of Style. Consider the following questions when writing your reflection:

1. Briefly describe how anxiety, fear, worry, and panic manifest physiologically, according to Brantley and Kasardo. 
2. How might understanding these physiological manifestations help one to cope with these intense emotions?

3. How might cultivating mindfulness help one to cope with and alleviate these intense emotions?

Week 5:

Application and Journal Reflection: Choose one of the tools presented in Altman's The Mindfulness Toolbox, and employ this tool every day. For six days, write a one-page journal entry on your experience incorporating this tool in your everyday routine. Consider the following questions when writing your journal reflections:

1. Was your selected tool difficult or easy to implement into your everyday routine?

2. What benefits did you experience from implementing the tool in your everyday routine, if any? Reflect on your emotional or physical state, concentration levels, energy levels, etc.

3. What negative results did you experience from implementing the tool in your everyday routine, if any? Reflect on your emotional or physical state, concentration levels, energy levels, etc.

4. Would you consider adopting this tool in your everyday life, and/or sharing this tool with current or future students?

5. How might adopting this tool help to cultivate mindfulness?

Week 6:

Application and Journal Reflection: Challenge yourself to develop awareness of your thoughts and to cultivate psychological flexibility this week. For six days, write a one-page journal entry on your experience incorporating psychological flexibility into your everyday routine. Write the journal entry at the same time everyday. Consider the following questions when writing your journal reflections, especially question \#4, throughout the entire week:

1. Was developing awareness of your thoughts and cultivating psychological flexibility easy or difficult to implement into your everyday routine?

2. What benefits did you experience from incorporating psychological flexibility into your everyday routine, if any? Reflect on your emotional or physical state, concentration levels, energy levels, etc.

3. What negative results did you experience from incorporating psychological flexibility into your everyday routine, if any? Reflect on your emotional or physical state, concentration levels, energy levels, etc.

4. On the fifth and sixth days did you notice a theme to your thoughts, whether negative or positive? Reflecting on the week, did you notice specific times within the day when cultivating psychological flexibility was easier or harder?

5. How might developing psychological flexibility help to cultivate mindfulness?

\section{Week 7:}

Inner Critic Tally Challenge: Download a free app that tracks tallies (Tally Counter or The Count), or use a small notebook that you can easily access during classes, practice sessions, rehearsal breaks, and study sessions. For three consecutive days ( 8 a.m. to 8 p.m.), mark a tally each time you notice a harsh, unproductive critique about yourself occur in your mind. Write a two-page double-spaced reflection on this challenge. Consider the following questions when writing your reflection: 
1. How many tallies did you total each day, and throughout the three days?

2. Did your tallies increase or decrease from day-to-day? Why do you think your tallies increased or decreased from day-to-day?

3. Did you mark tallies during specific times of the day? For example, did you mark more tallies during practice sessions instead of study sessions, or during rehearsals instead of classes?

4. How might the awareness of your inner critic's thoughts help to quiet your inner critic?

5. How might adopting this tool help to cultivate mindfulness?

Week 8:

Reflection: Write a three-page double-spaced reflection on the assigned readings for Week 8, and the guest lecturer's discussion. When citing material from the readings, include footnotes and proper citations in Chicago Manual of Style. Consider the following questions when writing your reflection:

1. Before you learned about perfectionism, did you associate perfectionism with success and positivity, or lack of success and negativity?

2. After reading the selections from Kogan's Nothing But the Best, what stories or descriptions resonated most with you? Do you think more musicians should publish more books and articles regarding the unproductive and negative side of perfectionism?

3. After reading the selections from Brown's The Gifts of Imperfection, what particular discussions or definitions of perfectionism resonated most with you? Do you believe you are a perfectionist? If so, what perfectionist qualities appear in your day-to-day life? (For example, your appearance, your preparation for lessons, rehearsals and/or recitals, your apartment/house, or all of the above)

4. After reading Orsillo's Acceptance and Mindfulness-based Approaches to Anxiety, how might finding acceptance alleviate perfectionism? How might cultivating mindfulness alleviate perfectionism?

Week 9:

Application and Journal Reflection: Be mindful of what experience(s), no matter how small or how brief, bring flow to your day-to-day routine. For six days, briefly write about the type of experience that brought you flow, and what factors contributed to experiencing flow.

For example: "I experienced flow while having coffee with a very good friend of mine. Our onehour coffee meeting felt five minutes long. I was engaged in the conversation by equally listening to her and contributing to the conversation. The conversation flowed nicely and offered moments of ponder and moments of laughter"

On the final day, write a one-page reflection on how the factors that contributed to your day-today flow might appropriately carry over to serving as contributing factors to experiencing flow in practice sessions and performances.

For example: "I recognized that during all of my flow experiences, I did not use my phone. My phone was on silent, was in another room, or was in my bag where I did not hear or see it. Due to this realization, I decided that during my practice sessions, I will leave my phone in my locker, or put it on airplane mode to avoid its distractions."

Week 10:

Application and Journal Reflection: Incorporate one of the breathing exercises that we employed in class, or one of the breathing exercises that you read about from the reading selections, prior 
to an experience that provokes stress, anxiety, nervousness, etc. for you (For example: a performance, a lesson, a rehearsal, a practice session, a date, a class, etc.). For six days, write a one-page journal entry on your experience incorporating this breathing exercise. Consider the following questions for each day:

1. Before implementing the breathing exercise: How do you feel? (For example, tense, calm, anxious, excited, or angry?)

2. While implementing the breathing exercise: Be mindful of thoughts or sensations that come up for you? Did any strong thoughts or sensations arise as you were implementing the breathing exercise?

3. After implementing the breathing exercise: How do you feel now?

4. Would you consider using this breathing exercise again? Why or why not?

5. How might breathing exercises help to cultivate mindfulness?

Week 11:

Reflection: Write a two-page double-spaced reflection on the assigned readings for Week 11, and the class period's discussion. When citing material from the readings, include footnotes and

proper citations in Chicago Manual of Style. Consider the following questions when writing your reflection:

1. Are you an introvert or extrovert? Do you agree or disagree with Laney's description of introverts and extroverts? How might understanding whether you're an introvert or extrovert determine your rest and sleep patterns?

2. After reading the selection from Loehr's The Power of Full Engagement, do you believe you have experienced burnout or are currently experiencing burnout? What does burnout feel like for you?

3. What surprised you most about the power of sleep after reading selections from Walker's Why We Sleep?

4. How might gaining adequate rest and sleep help to cultivate mindfulness?

Application and Journal Reflection: For six days, log your sleep patterns in your journal. Every night, write down how many hours of sleep you achieved the night before, if you took any naps, how much caffeine you consumed, and whether or not you dedicated time during the day to rest (rest can be defined as dinner with a good friend, a walk, a meditation, listening to music, closing your eyes for five minutes, etc.). Then, reflect on your productivity, activity, mood, and concentration levels in the morning, afternoon, and evening of each day.

Week 12:

Reflection: Write a two-page double-spaced reflection on the assigned reading for Week 12, and your experience with stress and recovery interval training at the recreation center. When citing material from the readings, include footnotes and proper citations in Chicago Manual of Style. Consider the following questions when writing your reflection:

1. What was your experience conducting the stress and recovery interval training activity?

2. Would you consider incorporating stress and recovery interval training into your exercise regimen? Why or why not?

3. How might developing the ability to recover more quickly and effectively during high stress events benefit one's practice sessions and performance experiences? 
4. How might improving the ability to recover more quickly and effectively during high stress events help to cultivate mindfulness?

Week 13:

Reflection: Write a two-page double-spaced reflection on the assigned reading for Week 13, and your experience in the yoga class. When citing material from the readings, include footnotes and proper citations in Chicago Manual of Style. Consider the following questions when writing your reflection:

1. What was your experience in the yoga class?

2. How might participating in a weekly yoga class benefit one's practice and performance experiences?

3. Would you consider participating in a weekly yoga class? Why or why not?

4. How might participating in yoga classes help to cultivate mindfulness?

Week 14:

Reflection: Write a two-page double-spaced reflection on the assigned reading for Week 14, and your experience meditating. When citing material from the readings, include footnotes and proper citations in Chicago Manual of Style. Consider the following questions when writing your reflection:

1. Consulting Kabat-Zinn's Wherever You Go, define meditation and discuss the difference between meditation and mindfulness.

2. What was your experience meditating?

3. How might employing meditation into an everyday routine benefit one's practice and performance experiences?

4. Would you consider mediating every day, even for just five minutes? Why or why not?

5. How might meditation help to cultivate mindfulness?

Week 15:

Final Reflection Paper: Write a five-page double-spaced reflection on your experience taking this course. When citing material from the readings, include footnotes and proper citations in

Chicago Manual of Style. Consider the following questions when writing your reflection:

1. What pre-conceptions did you have about mindfulness before taking this course?

2. What readings had the biggest impact on you as a musician and individual?

3. What experiences had the biggest impact on you as a musician and individual? (For example: meditation, yoga, inner critic challenge, or breathing exercises?)

4. What materials, exercises, and tools would you consider incorporating into your daily routine? 5 . What materials, exercises, and tools would you consider teaching your current or future students? 
Conclusion:

The introduction to Greene's book, Performance Success: Performing Your Best Under

Pressure, discusses how the advice, "just relax," for musicians entering an audition or performance is not effective:

The pressures of performing music are so intense, so daunting, that few in the business dare so much as broach the topic. It's taboo. As a musician you face a lifetime of auditions, competitions, recitals, solos, premieres, and debut appearances. Yours is a profession in which the slightest slip of the finger or quiver of the vocal chords can sour all the promise in the world. Yet utter the word anxiety backstage at a performance, and watch people's reactions. It's like you have kooties.

Divulge your inner fears in a private lesson, and the response may not be much more helpful. Many teachers prefer to stick to what they know best, which is music, not psychology. They want to help, but don't know how. So most sidestep students' apprehension. 'Just relax' is the conventionally proffered advice.

Relax at the Tchaikovsky competition? Relax when you've blown $\$ 900$ to fly across the country for your two-minute audition for the only symphony flute job to come open this year? Relax when your symphony job security depends on near-perfect technique in each and every concert until you're tenured? I don't think so. ${ }^{191}$

Encouraging oneself, a student, or a colleague to "just relax" usually has no positive impact on the individual. Therefore, after reading this document, the author hopes that readers recognize that mindfulness is not merely relaxation or paying attention. When cultivating mindfulness, a person is not forcing relaxation, but trying to stay in the present moment with awareness. Cultivating mindfulness requires consistent dedication, and serves as a continuous process, not a rehearsal that prepares an individual for a specific moment (like a recital or audition). When adopting a mindful lifestyle, musicians learn how to acknowledge, accept, and let go of thoughts, worries, emotions, and physical sensations experienced prior to and during practice sessions, rehearsals, and performances. ${ }^{192}$

${ }^{191}$ Greene, Performance Success, 1.

192 Kabat-Zinn, Wherever You Go, 22. 
Additionally, the author hopes for music teachers to better recognize the importance of sharing both their successful and unsuccessful performance experiences, and what routines or mindsets work best for them while practicing and performing. Music teachers can facilitate mindfulness in their students by helping them discover their strengths, shortcomings, and personality types, and demonstrating a mindful energy. Finally, the author wishes for readers to realize that many musicians experience music performance anxiety, panic, fear, and worry, that they harshly critique themselves, and that they have difficulty accepting their progress and skilllevels. The author hopes that musicians talk more openly about their struggles with these interruptive experiences that arise during practice sessions, rehearsals, and performances. If musicians openly discuss their musical and personal struggles, perhaps they will establish a breadth of knowledge, advice, and skills on how to cope with these intense emotions, thoughts, sensations, and behaviors, with the topic of mindfulness spearheading the discussion. 
Bibliography

Ackerman, Diane. Deep Play. New York: Random House, Inc., 1999.

Altman, Donald. The Mindfulness Toolbox: 50 Practical Tips, Tools and Handouts for Anxiety, Depression, Stress and Pain. Ashland: PESI Publishing and Media, 2014. ProQuest Ebook Central.

Ameli, Rezvan. 25 Lessons in Mindfulness: Now Time for Healthy Living. Washington D.C.: American Psychological Association, 2015.

Brantley, Jeffrey. Calming Your Anxious Mind: How Mindfulness and Compassion Can Free You from Anxiety, Fear, and Panic, $2^{\text {nd }}$ edition. Oakland: New Harbinger Publications, 2007. ProQuest Ebook Central.

Brown, Brene. The Gifts of Imperfection: Let Go of Who You Think You're Supposed to Be and Embrace Who You Are. Center City: Hazelden Publishing, 2010.

Coleman, Mark. Make Peace With Your Mind: How Mindfulness and Compassion Can Free Your Inner Critic. Novato: New World Library, 2016.

Csikszentmihalyi, Mihaly. Flow and the Foundations of Positive Psychology: The collected works of Mihaly Csikszentmihalyi. New York: Springer, 2014. Springer Ebooks.

Csikszentmihalyi, Mihaly. Finding Flow: The Psychology of Engagement with Everyday Life. New York: Basic Books, 1997.

Custodero, Lori, A. and Patricia A. St. John. "Actions Speak: Lessons Learned from the Systematic Observation of Flow Experience in Young Children's Music Making." In Listen to Their Voices: Research and Practice in Early Childhood Music, 2-18. Ontario: Canadian Music Educators' Association, 2007.

Falter, Ellie H. "Mindfulness: An Underused Tool for Deepening Music Understanding." General Music Today 30, no. 1 (2016): 20-24.

https://doi.org/10.1177/1048371316641461.

Fehm, Lydia and Katja Schmidt. "Performance Anxiety in Gifted Adolescent Musicians." Anxiety Disorders 1, no. 20 (Nov. 2004): 98-109.

https://doi.org/10.1016/j.janxdis.2004.11.011

Gardner, Frank and Zella E. Moore. "Mindfulness-Acceptance-Commitment (MAC) for Performance Development (PD).” In Clinical Sports Psychology, 97-111. Champaign: Human Kinetics, 2006. 
Gazella, Karolyn A. "Jon Kabat-Zinn, PhD Bringing Mindfulness to Medicine." Alternative Therapies in Health and Medicine 11, no. 3 (May 2005): 56-64. http://www.libproxy.wvu.edu/login?url=https://search-proquestcom.www.libproxy.wvu.edu/docview/204833586? accountid=2837.

Greene, Don. Performance Success: Performing Your Best Under Pressure. London: Routledge, 2001. ProQuest Ebook Central.

Greenland, Susan Kaiser. Mindful Games: Sharing Mindfulness and Meditation with Children, Teens, and Families. Boulder: Shambhala Publications, 2016.

Gross, Mike, Zella E. Moore, Frank L. Gardner, Andrew T. Wolanin, Rachel Pess and Donald R. Marks. "An empirical examination comparing Mindfulness-Acceptance-Commitment approach and Psychological Skills Training for the mental health and sport performance of female student athletes." International Journal of Sport and Exercise Psychology (Nov. 2016): 431-451. https://dx.doi.org/10.1080/162197X.2016.1250802.

Haid, Karen. "Coping with Performance Anxiety." Teaching Music 7, no. 1 (Aug. 1999): 40-42. ProQuest Central.

Kabat-Zinn, Jon. Wherever You Go, There You Are: Mindfulness Meditation in Everyday Life. New York: Hyperion, 2005.

Kageyama, Noa. "Becoming a Bulletproof Musician." Interview by MusicalU. MusicalU, December 19, 2018. Audio, 1:12:35. https:/www.musical-u.com/learn/becoming-abulletproof-musician-with-noa kageyama/?utm_source=mupod_shownotes\&utm_medium=podcast\&utm_campaign $=$ mupodcast.

Kageyama, Noa. The Bulletproof Musician. "Here's how it all began.” Accessed February 28, 2019. https://bulletproofmusician.com/about.

Kageyama. Noa. The Bulletproof Musician. "Mental Skills Assessment.” Accessed February 28, 2019. https://bulletproofmusician.com/assessment/msa15-results.

Kageyama, Noa. "Chapter 9: Evaluating Your Mental Strengths and Weaknesses with Dr. Noa Kageyama.” Interview by Troy Grady. Cracking the Code, Jan. 15, 2016. Audio, 2:46. https://troygrady.com/interviews/noa-kageyama/chapter-9-evaluate-yourmental-strengths-and-weaknesses.

Kogan, Judith. Nothing But The Best: The Struggle for Perfection at the Julliard School. New York: Random House, Inc., 1987.

Laney, Marti Olsen. The Introvert Advantage: How Quiet People Can Thrive in an Extroverted World. New York: Workman Publishing Company, 2002. 
Lecuona de la Cruz, Oscar and Raquel Rodriguez-Carajal. "Mindfulness and Music: A Promising Subject of an Un-Mapped Field." International Journal of Behavioral Research and Psychology (April 2014): 27-35. https://dx.doi.org/10.19070/2332-3000140006.

Loehr, Jim and Tony Schwartz. The Power of Full Engagement: Managing Energy, Not Time, Is the Key to High Performance and Personal Renewal. New York: The Free Press, 2003.

Llobet, Jaume Rosset and George Odam. The Musician's Body: A Maintenance Manual for Peak Performance. London: Guildhall School of Music and Drama, 2007.

Mayo Clinic. “Mayo Clinic.” Accessed April 19, 2019, https://www.mayoclinic.org.

MBCT. “About MBCT.” Accessed February 27, 2019. http://www.mbct.com/aboutmbct.html.

MBCT. "How will mindfulness practice help me?” Accessed February 27, 2019. http://www.mbct.com/how-will-mindfulness-practice-help-me.html.

Orsillo, Susan M. and Lizabeth Roemer, Acceptance and Mindfulness-based Approaches to Anxiety: Conceptualization and Treatment. New York: Springer, 2005. Springer Ebooks.

Osborne, Margaret S., Dianna T. Kenny. "The role of sensitizing experiences in music performance anxiety in adolescent musicians." Psychology of Music 36, no. 4 (April 2008): 447-462. https://doi.org/10.1177/0305735607086051.

Rappaport, Laury. "Mindfulness, Psychotherapy, and the Arts Therapies." In Mindfulness and the Arts Therapies: Theory and Practice, 24-37. London: Jessica Kingsley Publishers, 2013. ProQuest Ebook Central.

Serrano, Telmo and Helena Amaral Espirito-Santo. "Music, ballet, mindfulness, and psychological inflexibility." Psychology of Music 45, no. 5 (Feb. 2017): 725-738. https://doi.org/10.1177/0305735616689298.

Shonin, Edo, William Van Gordon, Nirbay N. Singh. Buddhist Foundations of Mindfulness. Switzerland: Springer International Publishing, 2015. Springer Ebooks.

Yoga Basics. "Hatha Yoga Pradipika,” Accessed February 22, 2019. http://www.yogabasics.com/learn/hatha-yoga-pradipika.

Yoga Basics. "History of Yoga.” Accessed February 22, 2019. http://www.yogabasics.com/learn/history-of-yoga. 
Yoga Basics. "Philosophy of Yoga." Accessed December 27, 2018. http://www.yogabasics.com/learn/philosophy-of-yoga.

Yoga Basics. "Yoga Styles: One Word Definitions.” Accessed February 22, 2019. http://www.yogabasics.com/connect/yoga-blog/yoga-styles-one-word-definitions.

Yoga Basics. "Yoga Therapy.” Accessed February 22, 2019. http://www.yogabasics.com/learn/yoga-therapy.

Waitzkin, Josh. The Art of Learning. New York: Simon and Schuster, 2007.

Walker, Matthew. Why We Sleep: Unlocking the Power of Sleep and Dreams. New York: Scribner, 2017.

Zizzi, Sam J. and Mark B. Anderson, Being Mindful in Sport and Exercise Psychology: Pathways for Practitioners and Students. Morgantown: FIT Publishing, 2017. 